ARTICLE

\title{
A non-catalytic scaffolding activity of hexokinase 2 contributes to EMT and metastasis
}

\author{
Catherine S. Blaha1,7, Gopalakrishnan Ramakrishnan ${ }^{1,7}$, Sang-Min Jeon (1) 2,7凶, Veronique Nogueira (D) ${ }^{1,7}$, \\ Hyunsoo Rho, Soeun Kang (D) 1, Prashanth Bhaskar', Alexander R. Terry (D) ${ }^{1}$, Alexandre F. Aissa (1) 1,

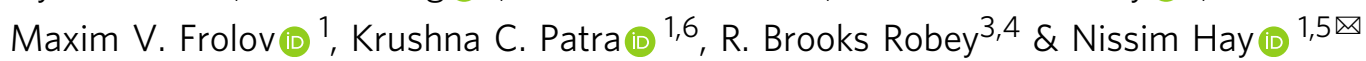

Hexokinase 2 (HK2), which catalyzes the first committed step in glucose metabolism, is induced in cancer cells. HK2's role in tumorigenesis has been attributed to its glucose kinase activity. Here, we describe a kinase independent HK2 activity, which contributes to metastasis. HK2 binds and sequesters glycogen synthase kinase 3 (GSK3) and acts as a scaffold forming a ternary complex with the regulatory subunit of protein kinase A (PRKAR1a) and GSK3 $\beta$ to facilitate GSK3 $\beta$ phosphorylation and inhibition by PKA. Thus, HK2 functions as an A-kinase anchoring protein (AKAP). Phosphorylation by GSK3 $\beta$ targets proteins for degradation. Consistently, HK2 increases the level and stability of GSK3 targets, MCL1, NRF2, and particularly SNAIL. In addition to GSK3 inhibition, HK2 kinase activity mediates SNAIL glycosylation, which prohibits its phosphorylation by GSK3. Finally, in mouse models of breast cancer metastasis, HK2 deficiency decreases SNAIL protein levels and inhibits SNAILmediated epithelial mesenchymal transition and metastasis.

\footnotetext{
${ }^{1}$ Department of Biochemistry and Molecular Genetics, College of Medicine, University of Illinois at Chicago, Chicago, IL 60607, USA. ${ }^{2}$ College of Pharmacy, Ajou University Yeongtong-gu, Suwon-si, Gyeonggi-do 443-749, Korea. ${ }^{3}$ Veterans Affairs Medical Center, White River Junction, Hartford, VT 05009, USA. ${ }^{4}$ Geisel School of Medicine at Dartmouth, Hanover, NH 03755, USA. ${ }^{5}$ Research \& Development Section, Jesse Brown VA Medical Center, Chicago, IL 60612, USA. ${ }^{6}$ Present address: Department of Cancer Biology, University of Cincinnati, Cincinnati, OH 45267-0521, USA. ${ }^{7}$ These authors contributed equally: Catherine S. Blaha, Gopalakrishnan Ramakrishnan, Sang-Min Jeon, Veronique Nogueira. ${ }^{凶}$ email: nhay@uic.edu; smjeon@ajou.ac.kr
} 
ncreased glucose uptake and intracellular glucose metabolism are known to occur in cancer cells in response to hyperactivation of signaling pathways ${ }^{1}$. However, little is known about retrograde signaling, whereby glycolytic enzymes regulate the activity of signaling enzymes. The first committed step in glucose metabolism is catalyzed by hexokinases. The phosphorylation of glucose by hexokinases determines the flux of glucose not only in glycolysis but also in the pentose phosphate pathway (PPP) and the hexosamine biosynthetic pathway ${ }^{2}$. Among the hexokinase isoforms hexokinase 1 (HK1) and hexokinase 2 (HK2) are mitochondria-associated, high affinity, low-Km hexokinases that couple oxidative phosphorylation and glycolysis. HK2 is expressed at relatively high levels during embryonic development and in cells derived from embryos but it ceases to be expressed in most adult tissues. Thus, while HK1 is widely expressed in adult mammalian tissues, HK2 is expressed only in a limited number of tissues. However, when normal cells are converted to cancer cells, they start expressing very high levels of HK2 in addition to the already expressed HK1. Therefore, HK2 expression is considered a hallmark of cancer cells that determines their high glycolytic flux. Thus far, the role of HK2 in tumorigenesis was attributed to its glycolytic activity ${ }^{3,4}$.

The low-Km hexokinases (HK1 and HK2) are inhibited by their own catalytic product, glucose-6-phosphate (G6P), which distinguishes them from glucokinase. G6P acts as an allosteric inhibitor of $\mathrm{HK} 1$ and $\mathrm{HK}^{5}{ }^{5,6}$. This feedback inhibition is likely instated to coordinate the uptake of glucose and ATP consumed to phosphorylate glucose with the cellular demand for glucose as a carbon source for energy and building blocks for anabolic processes. Notably, G6P mimetics could be used to target HK2 glycolytic activity for cancer therapy ${ }^{4,7}$. Buildup in G6P level may occur in a temporal manner or when the flux downstream of G6P is attenuated or inhibited. The substitution of 2-deoxyglucose (2-DG) for glucose results in 2-deoxyglucose-6-phosphate (2-DG6P) accumulation because 2-DG6P cannot be further metabolized in glycolysis. Although 2-DG6P is less efficient than G6P in inhibiting HK1 and HK2, its rapid accumulation to relatively high amounts inside cells inhibits HK1 or $\mathrm{HK}_{2}{ }^{8,9}$. Thus, $2-\mathrm{DG}$ can be used to study the consequences of the allosteric inhibition and conformational change of HK1 and HK2 by their own catalytic product. Using this approach, we uncovered a novel mechanism by which HK2 affects the activity of glycogen synthase kinase 3 (GSK3).

GSK3 is a Ser/Thr kinase, which plays a crucial role in many vital cellular processes, such as cell proliferation, apoptosis, metabolism, and cancer progression. There are two isoforms of GSK3 ( $\alpha$ and $\beta$ ) encoded by two separate genes. The kinase activity of GSK3 is inhibited by phosphorylation of the protein at Ser21/Ser9 (corresponding residues in GSK3 $\alpha / \beta$ ). The phosphorylation of GSK3 on these residues is mediated by several AGC kinases ${ }^{10-14}$, and by Ser/Thr phosphatases such as protein phosphatase 1 (PP1) and protein phosphatase $2 \mathrm{~A}(\mathrm{PP} 2 \mathrm{~A})^{15}$.

Our results showed that HK2 sequesters GSK3 inhibiting its activity and accessibility to its targets. Importantly, we demonstrated that HK2 directly binds GSK3 $\beta$ and the cyclic-AMP-dependent protein kinase A (PKA) regulatory subunit la (PRKAR1a) to facilitate GSK3 $\beta$ phosphorylation by PKA. In vitro, HK2 forms a complex with PRKAR1a, GSK3 $\beta$, and PKA catalytic subunit that promotes the phosphorylation of GSK3 $\beta$ by cyclic AMP. Thus, HK2 functions as AKAP, independently of its catalytic activity. However, G6P, which is known to allosterically change HK2, disrupts the binding of HK2 to GSK3 $\beta$ and PRKAR1a. In vivo, the accumulation of G6P or 2DG6P, dramatically reduced the inhibitory phosphorylation of GSK3 $\alpha$ and GSK3 $\beta$ on Ser21 or Ser9 respectively by dissociating GSK3 and increasing its susceptibility to PP2A.

Phosphorylation of proteins by GSK3 often targets them for degradation ${ }^{16}$. Consistent with the effect of HK2 on GSK3 activity, we found that HK2 affects the level and stability of MCL-1, NRF2, and SNAIL, which are known GSK3 targets ${ }^{17-19,20}$. The stability of SNAIL was particularly affected because in addition to the direct effect of HK2 on GSK3 activity, HK2 mediates SNAIL's glycosylation, which decreases its susceptibility to phosphorylation by GSK3. Consistently we found that the depletion of HK2 in mouse models of breast cancer metastasis inhibited metastasis via decreased SNAIL protein level and its effect on EMT. Finally, our results showing that systemic HK2 deletion after tumor onset, which emulates drug therapy, inhibited breast cancer metastasis provided a proof of concept for targeting HK2 to inhibit breast cancer metastasis.

\section{Results}

The glucose analog 2-deoxyglucose (2-DG) inhibits the phosphorylation of glycogen synthase kinase 3 (GSK3) and increases its activity. The replacement of glucose with two different glucose analogs, 2-DG and 5-thioglucose (5-TG), revealed a rapid reduction in the phosphorylation of GSK3 $\beta$ specifically by $2-D G$, and not by 5-TG, in both Ratla cells and mouse embryo fibroblasts (MEFs) (Fig. 1a). Although neither 2-DG nor 5-TG can be metabolized in glycolysis, 2-DG can be phosphorylated to 2-DG6P by hexokinase, whereas 5-TG, although binds hexokinase, cannot be phosphorylated by hexokinase (Fig. 1b). The effect of 2-DG on both GSK3a and GSK3 $\beta$ phosphorylation was observed in all rodent and human cell lines that were tested (Supplementary Fig. 1).

GSK3 is a versatile kinase that participates in many fundamental cellular processes, such as cell proliferation, cell growth, and cell survival ${ }^{11,21}$. In many cases the phosphorylation of proteins by GSK3 targets them for degradation. For instance, GSK3 was shown to regulate the stability of the anti-apoptotic protein Mcl-1 through direct phosphorylation ${ }^{17}$. Indeed, we found that replacement of glucose with 2-DG markedly and rapidly reduced the level of $\mathrm{Mcl}-1$ (Fig. 1c).

HK2 maintains a high level of GSK3 phosphorylation independent of its activity, but its activity is required for the suppression of GSK3 phosphorylation by 2-DG. Unlike 5-TG, 2-DG can be phosphorylated by hexokinase, so we examined whether hexokinase activity is required for the inhibitory effect of 2-DG on GSK3 $\beta$ phosphorylation. We took advantage of MI5-4 $\mathrm{CHO}$ cells $^{22}$, which lack detectable hexokinase expression and have limited hexokinase activity, and ectopically expressed either wildtype HK2 (WT HK2) or HK2 mutants in these cells. HK2-DA is a mutant in which alanine is substituted for two aspartic acid residues in the amino- and carboxy-terminal domains of HK2 required for the binding of glucose (D209A/D657A). HK2-SA is a mutant in which alanine is substituted for two serine residues in the aminoand carboxy-terminal domains required for catalytic activity $(\mathrm{S} 155 \mathrm{~A} / \mathrm{S603A})^{23}$. HK2-dMT is a mutant that carries a deletion of the first 20 amino acids, which are required for binding to VDAC and mitochondria. When expressed in MI5-4 CHO cells, both WT HK2 and dMT mutant of HK2 had catalytic activity, whereas the DA and SA mutants had very little or no catalytic activity (Supplementary Fig. 2a). As shown in Fig. 1d and Supplementary Fig. 2b, $2-D G$ had no effect on GSK3 $\beta$ phosphorylation in MI5-4 CHO cells expressing vector alone. However, expression of WT HK2 in these cells elevated GSK3 $\beta$ phosphorylation in the presence of glucose, but GSK3 $\beta$ phosphorylation was decreased in the presence of 2-DG. Surprisingly, both WT HK2 and kinase inactive HK2 mutants increased GSK3 $\beta$ phosphorylation in the presence of glucose (Fig. 1d). However, the replacement of glucose with 2-DG reduced GSK3 $\beta$ phosphorylation in cells expressing kinase-active WT HK2 or the mitochondrial binding-deficient mutant (dMT-HK2) and, to a much lesser extent, in cells expressing kinase-inactive mutants (Fig. 1d, and Supplementary Fig. 2b). Interestingly, overexpression 
a

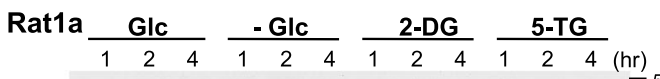

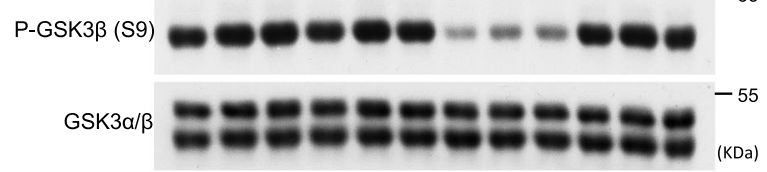

MEFS Glc - 2-DG 5-TG

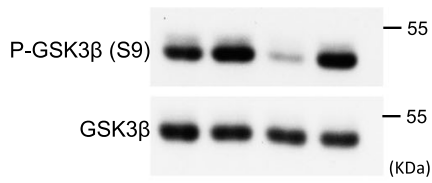

C

2-DG (10mM)
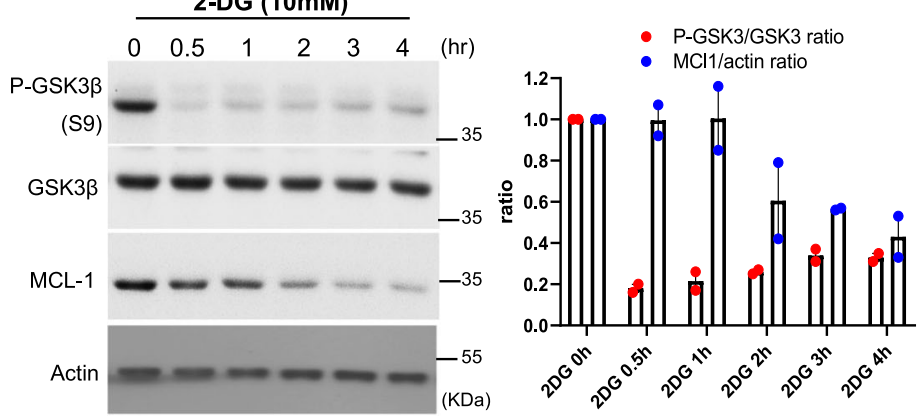

e

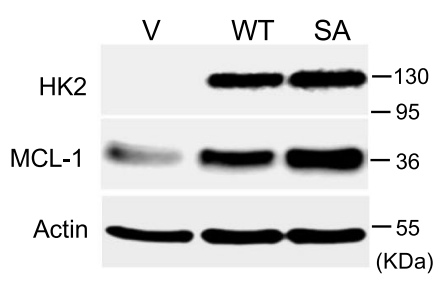

f

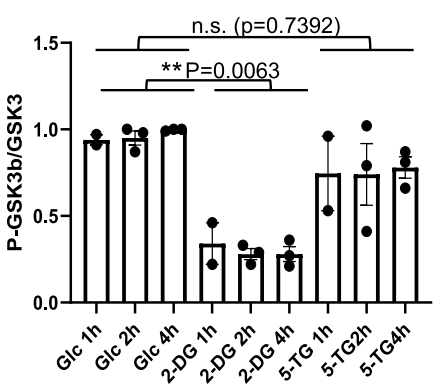

b

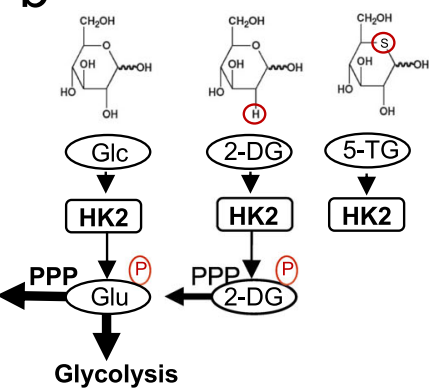

d
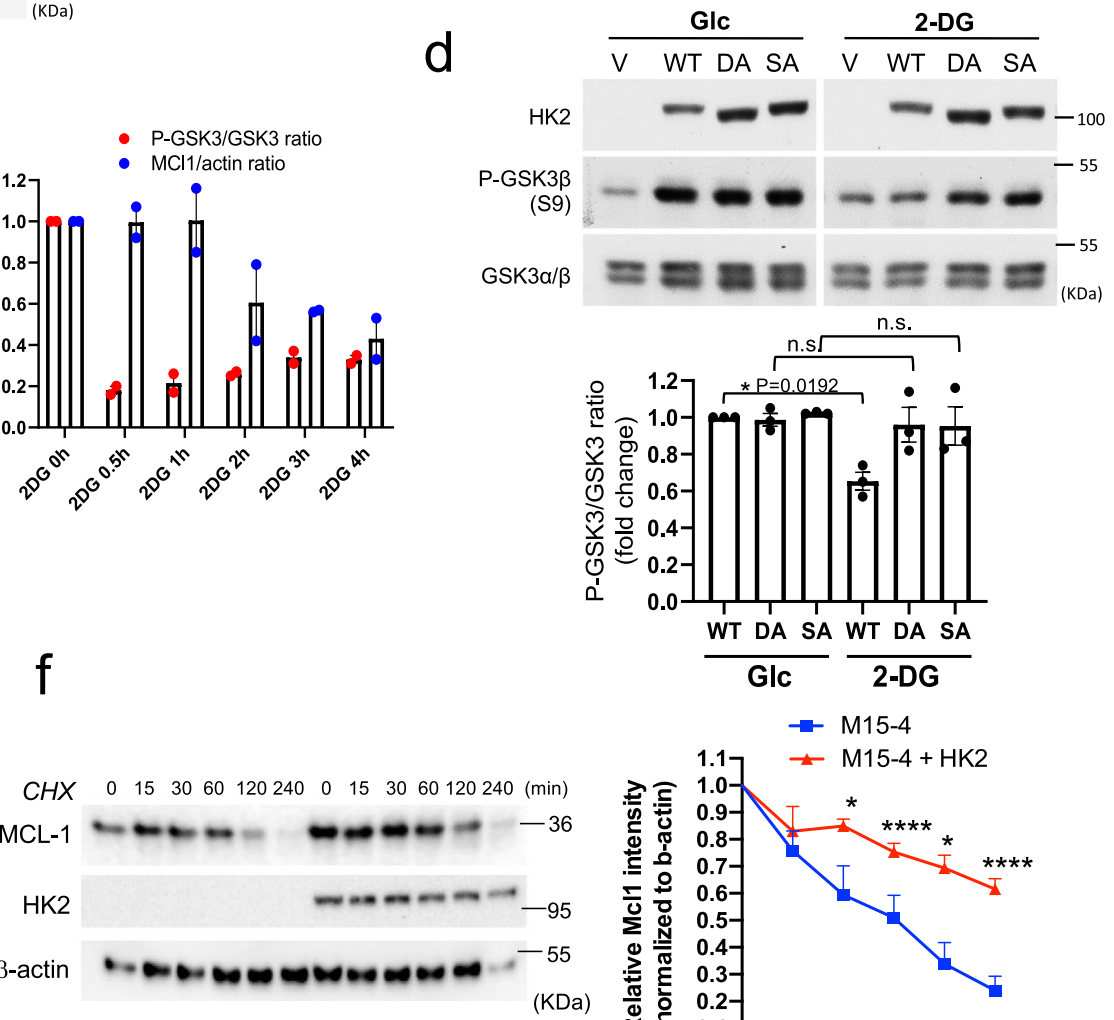

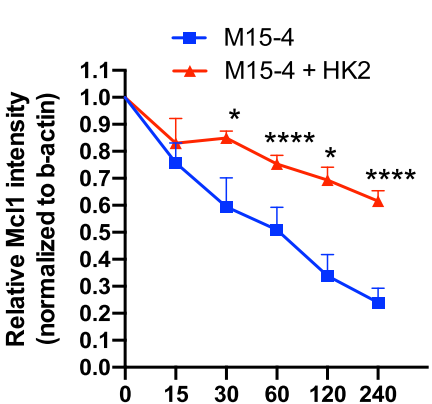

$\mathrm{CHX}$ treatment time in minutes

Fig. 1 Replacement of glucose with 2-DG inhibits the phosphorylation of GSK3 and increases GSK3 activity in a HK2-dependent manner. a Rat1a cells or MEFs were incubated in glucose-free medium in the absence (-) or presence of $10 \mathrm{mM}$ glucose (Glc), 2-DG or 5-TG. Immunoblots showing GSK3 $\beta$ phosphorylation, at the indicated time points after incubation. Bar graph shows densitometric quantification of $p G S K 3 \beta / G S K 3 \alpha / \beta$ ratio from three independent experiments in Rat1a cells $(n=3)$. Data are presented as the mean \pm SEM. ${ }^{\star \star} p=0.0063 ;$ n.s. $p=0.7392 ;$ one-way ANOVA was used to calculate significance. $\mathbf{b}$ Schematic depicting the structures of glucose (Glc), 2-DG, and 5-TG and their utilization by HK inside cells. Like Glc, 2-DG can be phosphorylated by HK2 but cannot be further metabolized except in the first step of the pentose phosphate pathway (PPP). 5-TG cannot be phosphorylated by HK2. c Rat1a cells were incubated in glucose-free medium in the presence of $10 \mathrm{mM} 2-\mathrm{DG}$ for the indicated durations. Cells were then harvested for immunoblotting to determine GSK3 $\beta$ phosphorylation and MCL1 levels. Bar graph shows quantification from two independent experiments. d MI5-4 CHO cells expressing either wild-type (WT) HK2, individual kinase-dead HK2 mutants (DA, SA) or empty vector (V) were incubated in glucosefree medium in the presence of $10 \mathrm{mM}$ glucose (G) or 2-DG (D). After $2 \mathrm{~h}$, cells were harvested and analyzed for immunoblotting. Bar graph shows relative densitometric quantification of $\mathrm{pGSK} 3 \beta / \mathrm{GSK} 3 \alpha / \beta$ ratio $(\mathrm{WT}, \mathrm{DA}, \mathrm{SA})$. Results are the mean $\pm \mathrm{SEM}$ of three independent experiments. ${ }^{*} p=0.0192$; oneway ANOVA was used to calculate significance. e Representative immunoblot of three independent experiments showing the level of the MCL-1 protein after expression of WT or kinase-dead SA mutant HK2 in MI5-4 CHO cells. f Protein stability of MCL-1 in MI5-4 CHO cells and MI5-4 CHO cells expressing WT HK2 as measured after exposure to cycloheximide (CHX). Plot showing MCL1 protein half-life after quantification relative to $\beta$-actin. Data are presented as the mean \pm SEM. ${ }^{\star} p<0.05$ ( $p=0.0272$ for 30 min and $p=0.0151$ for $\left.120 \mathrm{~min}\right)$, ${ }^{\star \star \star \star} p<0.0001$ versus 0 h; two-way RM ANOVA test was performed to calculate the significance ( $n=3$ independent experiments). Uncropped blots are provided as a Supplementary Fig. 16. Source data are provided as a Source Data file. 
of WT HK2, kinase-inactive HK2 mutants, or a mitochondrial binding-deficient mutant of HK2 even in cells that express endogenous hexokinases, such as Ratla and HEK-293 cells, also increased GSK3 $\beta$ phosphorylation (Supplementary Fig. 3a, b). However, in all cell lines tested, 2-DG markedly reduced GSK3 $\beta$ phosphorylation only in cells expressing kinase-active HK2 (Fig. 1d and Supplementary Fig. 3a, b). Taken together, these results indicate that high-level expression of HK2 can elevate the phosphorylation of GSK3 $\beta$ in a kinase-independent manner, while 2-DG markedly inhibits GSK $3 \beta$ phosphorylation only in the presence of a catalytically active hexokinase. The ability of HK2 to affect GSK3 $\beta$ phosphorylation appears to be independent of its binding to mitochondria. Therefore, these data strongly suggest that the effect of 2-DG on GSK3 phosphorylation is dependent upon 2-DG6P. Moreover, this can explain why 5-TG had no effect on the phosphorylation of GSK3, as unlike 2-DG, 5-TG cannot be phosphorylated. (See Fig. 1a, b). Consistent with the effect of HK2 on GSK3 phosphorylation and activity, we found that the expression of either WT or mutant HK2 in MI5-4 CHO cells markedly increased the steady state levels and stability of Mcl-1 (Fig. 1e, f).

The effects of HK2 and 2-DG on GSK3 $\beta$ phosphorylation are mediated by PKA and PP2A. The phosphorylation of GSK3 $\beta$ on Ser9, leads to its inhibition and is mediated by several AGC kinases, in particular AKT, PKA, and p70S6K (S6K1) ${ }^{10-14}$, as well as Ser/Thr protein phosphatases such as PP1 and PP2A ${ }^{15}$. To understand the mechanism by which GSK3 phosphorylation is affected, we first determined, which of the known kinases that phosphorylate GSK3 $\beta$ on Ser9 might be involved. Akt is considered a predominant kinase that phosphorylates GSK3. However, we excluded Akt involvement because 2-DG inhibited GSK3 $\beta$ phosphorylation independently of Akt activity (Supplementary Fig. $4 \mathrm{a}-\mathrm{c}$ ). First, $2-\mathrm{DG}$ reduced GSK3 $\beta$ phosphorylation despite a corresponding increase in Akt activation. Second, although the complete depletion of Akt activity in Akt1/2 DKO MEFs by LY294002 (PI3-kinase inhibitor) treatment reduced GSK3 $\beta$ phosphorylation in the presence of glucose, it was further reduced when glucose was replaced with 2-DG. Finally, the overexpression of a constitutively activated form of Akt (mAkt) was associated with GSK3 $\beta$ phosphorylation but was largely amenable to 2-DG inhibition. Taken together, these findings suggest that the effects of $2-D G$ on GSK3 $\beta$ phosphorylation and activation are not dependent on Akt.

In an unbiased yeast two-hybrid screen, where a full length HK2 was used as a bait, we found that a protein fragment containing the first 129 amino acids, which encompasses the dimerization/docking domain of PRKAR $1 \mathrm{a}^{24}$, the regulatory subunit of PKA, interacts with HK2 (Supplementary Fig. 5). Therefore, we next explored the possibility that the effect of 2-DG6P on GSK3 $\beta$ phosphorylation is mediated by PKA. PRKARla (RIa) binds the catalytic subunit of PKA and restrains its activity, but upon binding of cyclic-AMP, the catalytic subunit is dissociated from PRKAR1a, enabling the phosphorylation of PKA target proteins ${ }^{25}$. We, therefore, focused on the possibility that the effect of HK2 on GSK3 phosphorylation is mediated by PKA. We examined the effect of the adenylate cyclase inhibitor, $2^{\prime}$ $5^{\prime}$-dideoxyadenosine on the ability of $\mathrm{HK} 2$ to increase the phosphorylation of GSK3. As shown in Fig. 2a, the increase in GSK3 phosphorylation following overexpression of HK2 in MI5$4 \mathrm{CHO}$ cells was blunted in the presence of the adenylate cyclase inhibitor $2^{\prime} 5^{\prime}$-dideoxyadenosine. We then used the PKA inhibitor H-89 and found that it reduced GSK3 phosphorylation mediated by HK2 (Fig. 2b). Notably H-89, at the concentration that was used $(10 \mu \mathrm{M})$, did not inhibit the activity of Akt, S6K1, and RSK as measured by p-Akt, p-S6K1, and p-RSK, which can phosphorylate GSK3, while inhibiting PKA as measured by p-CREB and p-VASP1 $1^{26,27}$ (Supplementary Fig. 6). Furthermore, while inhibiting PKA, H-89 activated S6K1, consistent with recent report ${ }^{28}$, further supporting the notion that the induced GSK3 phosphorylation is mediated by PKA and not by Akt or S6K1. To further understand the mechanism by which HK2 affects GSK3 phosphorylation through PRKAR1a, we used immunoprecipitation experiments with HK2 and PRKAR1a to confirm the yeast two-hybrid results. Indeed, we found that HK2 bound PRKAR1a in the presence of glucose, but this binding was inhibited when glucose was replaced with 2-DG (Fig. 2c). As shown in Fig. 2d and Supplementary Fig. 7a, ectopically expressed HK2 also pulled down ectopically expressed GSK3 $\beta$ in the presence of glucose but not in the presence of 2-DG. Both the WT or active GSK3 $\beta$ mutant bound HK2 in the presence of glucose, but to a much lesser extent in the presence of 2-DG (Supplementary Fig. 7a). In a reciprocal experiment, GSK3 $\beta$ pulled down HK2 (Supplementary Fig. 7b). Notably, GSK3 $\beta$ was phosphorylated when was bound to HK2 (Supplementary Fig. 7a). Finally, when exogenous HK2 was immunoprecipitated, it pulled down endogenous PRKAR1a, but only in the presence of glucose and not in the presence of 2-DG (Fig. 2e). Importantly, when MI5-4 CHO cells were treated with 2-DG, GSK3 $\beta$ was dissociated from only the catalytically active HK2 but not from the kinasedead HK2 mutants (Supplementary Fig. 7c). This is consistent with the results showing that 2-DG markedly decreased GSK3 $\beta$ phosphorylation only when kinase-active HK2 was expressed but not when the kinase-dead HK2 mutant was expressed (Fig. 1d and Supplementary Fig. 3). To verify that endogenous HK2 binds endogenous GSK3 $\beta$, we immunoprecipitated endogenous HK2 from HEK293 cells and found that it interacted with endogenous GSK3 $\beta$, but this interaction did not occur when glucose was replaced with 2-DG (Fig. 2f, see also Supplementary Fig. 15c). Taken together, these results raise the possibility that the binding of PRKAR1a and GSK3 $\beta$ to hexokinase increases the susceptibility of GSK3 $\beta$ to PKA-mediated phosphorylation in a cyclic AMP- and PKA-dependent manner. However, conformational changes in HK2 in response to 2-DG6P or glucose-6-phosphate (G6P) binding inhibits the interaction between HK2, PRKAR1a, and GSK $3 \beta$ and thereby decreases GSK3 $\beta$ phosphorylation.

Since both the protein phosphatase 1 (PP1) and protein phosphatase 2A (PP2A) phosphatases also regulate GSK3 phosphorylation $^{15}$, we examined their potential involvement in the effect of hexokinase on GSK3 $\beta$ phosphorylation. Treatment of cells with the PP2A inhibitor okadaic acid (OA) or the PP1 inhibitor tautomycetin (TC) revealed that treatment with $100 \mathrm{nM}$ of OA markedly increased GSK3 $\beta$ phosphorylation in the presence of glucose but also blunted the decrease in GSK3 phosphorylation after glucose was replaced with 2-DG (Supplementary Fig. 8a). TC failed to mimic these effects at concentration as high as $500 \mathrm{nM}$ (Supplementary Fig. 8a), but the specific PP2A inhibitor LB100 inhibited the effect of 2-DG on GSK3 $\beta$ phosphorylation (Supplementary Fig. 8b), suggesting PP2A involvement in the dephosphorylating effect of $2-\mathrm{DG}$ on GSK3 $\beta$. Endogenous PP2A interaction with GSK3 $\beta$ dissociated from HK2 in the presence of 2-DG (Fig. $2 \mathrm{~g}$ ) is compatible with this interpretation. These results indicate that HK2 facilitates GSK3 inhibition not only via PKA-mediated phosphorylation, but also via physical GSK3 sequestration and the associated prevention of its dephosphorylation and activation by PP2A.

HK2 forms complexes with GSK3 $\beta$ and PRKAR1a (RIa) in vitro in a G6P-dependent manner, indicating direct binding. As was shown for bone-fide AKAPs, the ultimate definition of AKAP is determined by its ability to bind directly to the PKA 


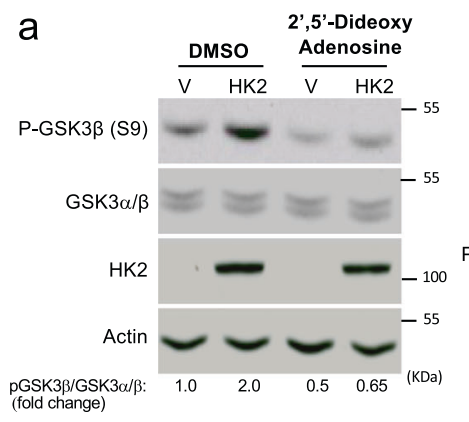

d

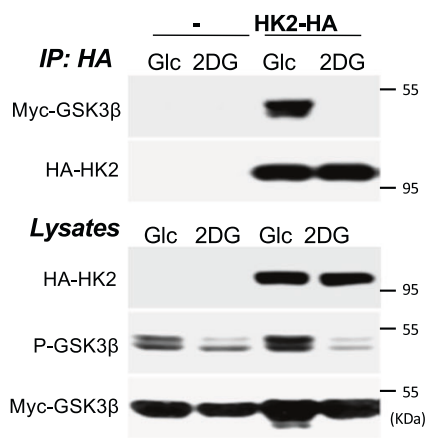

b

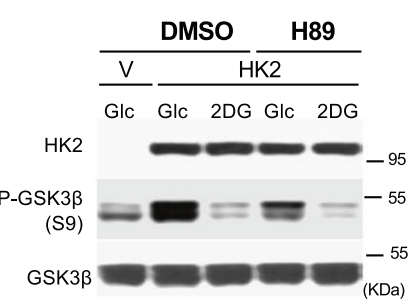

e

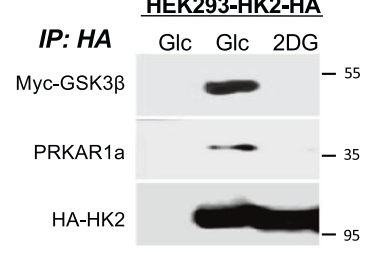

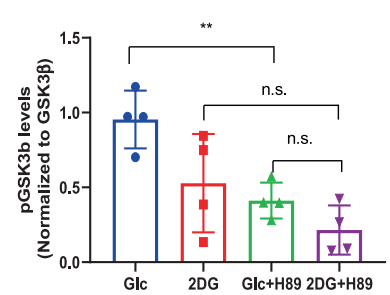

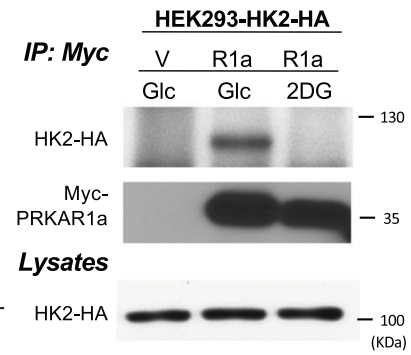

f

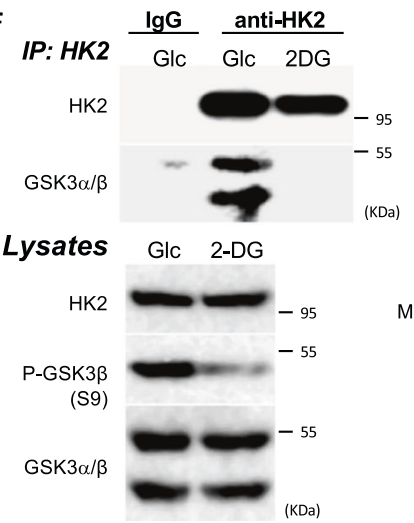

\section{g}

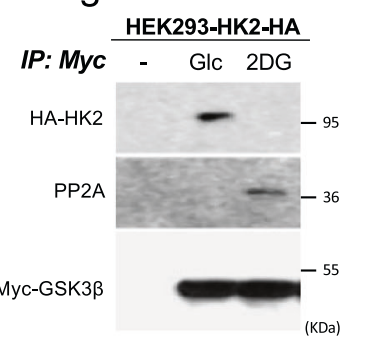

Fig. 2 HK2 affects GSK3 $\beta$ phosphorylation in a PKA-dependent manner and interacts with PRKAR1a and GSK3 $\beta$ in a 2-DG-dependent manner.

a Immunoblot showing GSK3 $\beta$ phosphorylation following HK2 expression in MI5-4 cells in the presence of the adenylate cyclase inhibitor 2'5'-

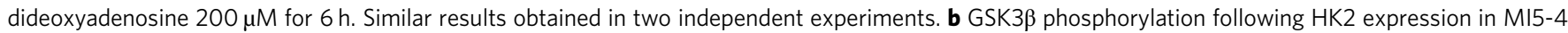

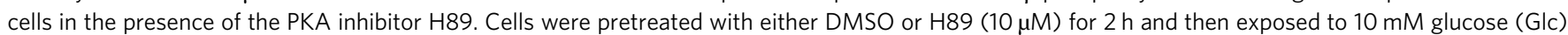
or 2 DG for another $2 \mathrm{~h}$ in the presence of either DMSO or $\mathrm{H} 89$ (left panel: representative immunoblot; right panel: quantification of pGSK3 $\beta / G S K 3 \beta$ ). Results are the mean \pm SEM of three independent experiments. ${ }^{\star \star} p=0.008, n . s .=0.1215$; one-way ANOVA was used to calculate significance. $\mathbf{c}$ After transfection of control myc-tagged vector (V) or myc-tagged PRKAR1a (R1a) or control myc-vector plasmid into HEK293 cells stably expressing HA-tagged HK2 (HEK293-HK2-HA), cells were incubated in glucose-free medium in the presence of 10 mM glucose (Glc) or 2-DG. After 2 h, cells were lysed for

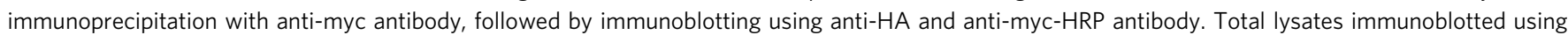
anti-HA antibody. Similar results obtained in two independent experiments. d Control or HEK293-HK2-HA cells were transfected with myc-GSK3 $\beta$ expression vector. Cells were treated, and lysed for immunoprecipitation as in c. Total lysates immunoblotted using anti-p-GSK3 $\beta$, anti-myc-HRP, and anti$\mathrm{HA}$ antibodies. Similar results obtained in two independent experiments. e After transfection of myc-GSK3 $\beta$ into HEK293-HK2-HA cells, cells were incubated in glucose-free medium in the presence of $10 \mathrm{mM}$ glucose (Glc) or 2-DG. After $2 \mathrm{~h}$, cells were lysed for immunoprecipitation with anti-HA antibody, followed by immunoblotting using anti-myc-HRP antibody and anti-PRKAR1a antibody. First lane shows control untransfected cells. Similar

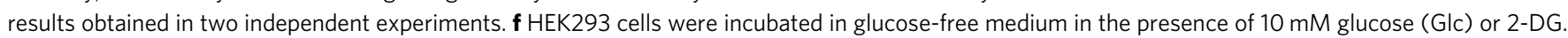

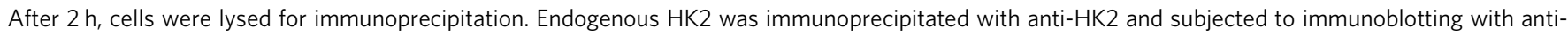
HK2 and anti-GSK3 $\alpha / \beta$. Similar results obtained in two experiments. $\mathbf{g}$ The experiment was performed as described in $\mathbf{d}$, except that after immunoprecipitation with anti-myc, immunoblotting was performed with anti-PP2A. Similar results in two experiments. Uncropped blots are provided as a supplementary Fig. 16. Source data are provided as a Source Data file.

regulatory subunits together with the target protein. To further determine if HK2 can be categorized as AKAP, we conducted in vitro binding assays as previously described ${ }^{29}$. We employed Histagged or GST-tagged protein coated plates. The plates were subjected to the interacting proteins and interaction was determined by fluorescent anti-tagged antibodies against the interacting protein (Fig. 3, left panels). As shown in Fig. 3a anchored RIa binds the increasing amounts of $\mathrm{HK} 2$, but this interaction was disrupted after addition of G6P. Likewise, anchored GSK3 $\beta$ binds HK2, and this binding is disrupted by the addition of G6P (Fig. 3b). Finally, anchored RIa binds GSK3 $\beta$ only when HK2 is present to form a ternary complex (Fig. 3c). This complex is also sensitive to the addition of G6P but to a less extent than the individual complexes suggesting that the ternary complex is more resistant to the allosteric inhibition of HK2. To determine if the ternary complex can bind the catalytic PKA subunit (PKAc), we added PKAc to the tethered complex and showed that it binds in an HK2 and RIa-dependent manner (Fig. 4a). Furthermore, addition of cAMP markedly induced the phosphorylation of GSK3 $\beta$ in the complex, which was diminished by G6P (Fig. 4b). Therefore, collectively, these results provide strong evidence that the binding of HK2 to GSK3 $\beta$ and RIa is direct and that HK2 is a bone-fide AKAP.

The majority of AKAPs have dual specificity for the regulatory subunits of PKA, RIa and R2a, whereas a subset of AKAPs bind RIa only $^{30}$. Our results showed that HK2 binds exclusively R1a for the following reasons: first, we subjected the complex of HK2-R1a to the AKAP disruptor, FMP-API-1, which disrupt either R1a or R2a from the dual specificity AKAPs ${ }^{31}$. We found that FMP-API-1 could not disrupt HK2-RIa interaction in vitro (Supplementary Fig. 9a). Second, RIAD, the specific R1a disruptor ${ }^{32}$, disrupt the complex (Supplementary Fig. 9b). Finally, we showed that R2a binds poorly HK2 in comparison with R1a (Supplementary Fig. 9c).

Glucose flux could determine the effect of HK2 on GSK3 phosphorylation. The results described above showed that in the presence of glucose HK2 elevates GSK3 phosphorylation through its interaction with GSK3 and PKA (which phosphorylates GSK3). 

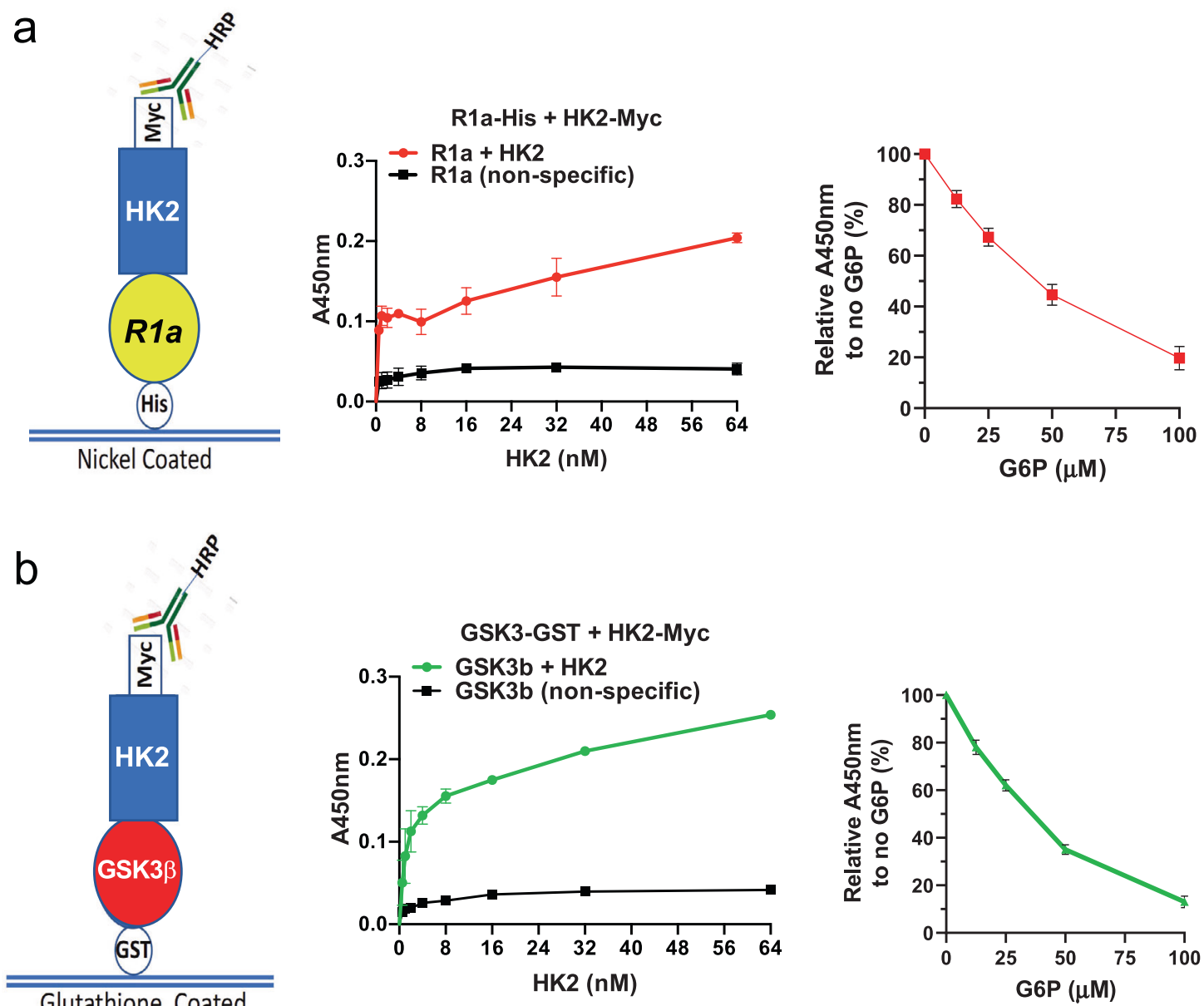

Glutathione Coated
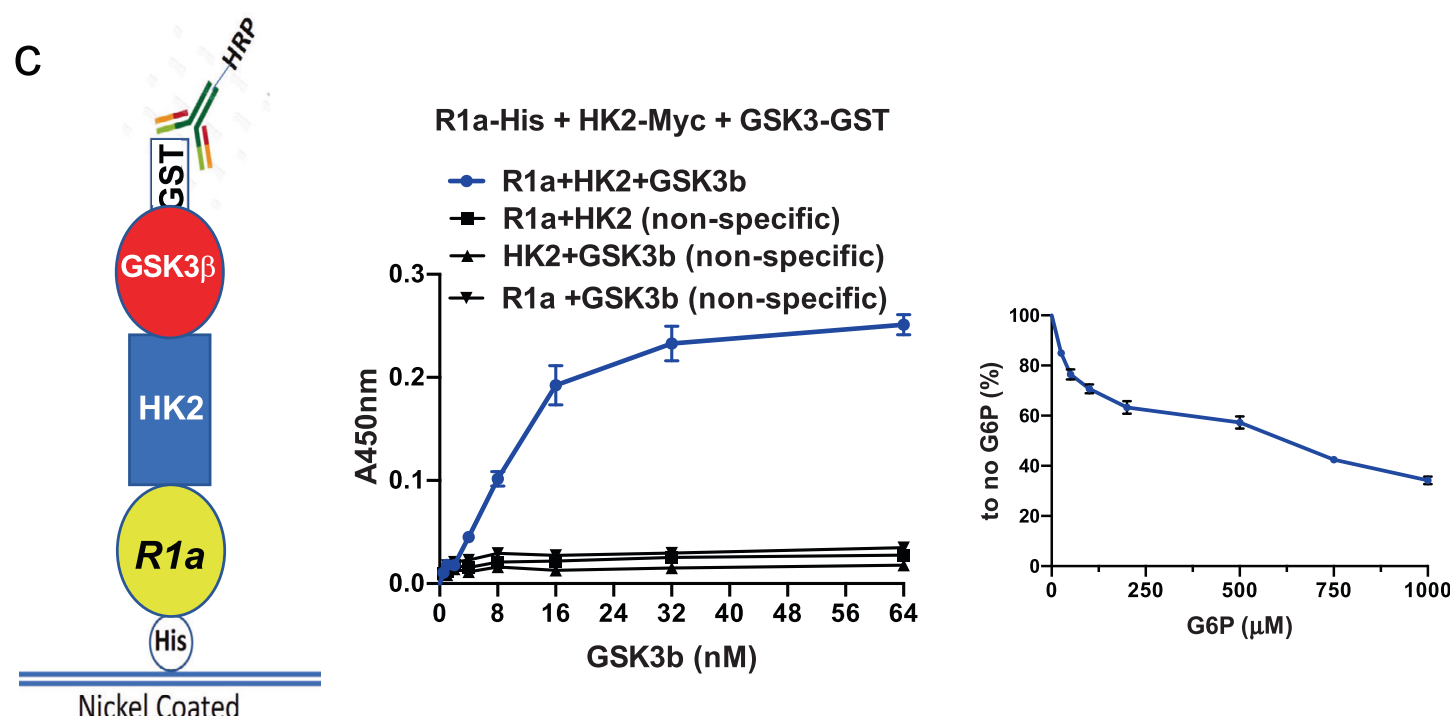

Nickel Coated

This effect on GSK3 phosphorylation is independent of either hexokinase activity or binding to the mitochondria. However, the replacement of glucose with 2-DG inhibited GSK3 phosphorylation through a mechanism that was dependent on hexokinase activity and the phosphorylation of 2-DG to 2-DG6P. Unlike G6P, 2-DG6P is not utilized in glycolysis and therefore accumulates and binds HK2 to elicit conformational changes that promote the dissociation of GSK3 and RIa. If this hypothesis is correct, it is expected that a reduction in glucose metabolism flux in a way that causes G6P accumulation should reduce GSK3 phosphorylation. Therefore, we inhibited the flux of glucose metabolism by exposing the cells to 6-aminonicotinamide (6-AN). 6-AN inhibits 6-phosphogluconate dehydrogenase (6-PGDH), which results in the accumulation of 6-phosphogluconate (6-PG). 6-PG is a competitive inhibitor of phosphoglucose isomerase (PGI), and its inhibition is known to induce G6P accumulation ${ }^{33-35}$ (Fig. 5a). Indeed, we found a marked reduction in GSK3 $\beta$ phosphorylation following treatment with 6-AN (Fig. 5b, d and Supplementary 
Fig. 3 HK2 directly binds GSK3 $\beta$ and R1a in vitro to form complexes that are disrupted by G6P. a Nickel-coated 96-well plates were incubated overnight at $4{ }^{\circ} \mathrm{C}$ with His-PRKAR1a $(50 \mathrm{nM})$ and then incubated with Myc-HK2 (0.25-64 nM) in blocking buffer or with blocking buffer without HK2. HK2 binding was detected and quantified with anti-Myc-HRP-conjugated antibody, and an HRP-catalyzed reaction with a chromogenic substrate solution. Left panel shows generated binding curves. Curves were fitted based on a one-site-binding model in GraphPad Prism followed by a comparison of fits with $p<0.0001$. Right panel: binding curve after increasing concentrations of G6P. Binding was conducted as above except that Myc-HK2 (32 nM) was incubated for $2 \mathrm{~h}$. Thirty minutes before the end of Myc-HK2 incubation, increasing concentrations of G6P were added to the wells and detection was carried out as above. Results are the mean \pm SEM of three independent experiments. $p<0.0001$ one-way ANOVA. b Glutathione-coated 96 -well plates were incubated overnight at $4{ }^{\circ} \mathrm{C}$ with GST-GSK3 $\beta(50 \mathrm{nM})$ and then incubated with or without Myc-HK2 $(0.25-64 \mathrm{nM})$. Binding was quantified in a. Left panel: binding curves were generated as in a (comparison of fits with $p<0.0001$ ). Right panel: binding curve after increasing concentrations of $\mathrm{G} 6 \mathrm{P}$ as described in $\mathbf{a}$. Results are the mean \pm SEM of three independent experiments. $p<0.0001$ one-way ANOVA. c Nickel-coated 96 -well plates were incubated overnight at $4{ }^{\circ} \mathrm{C}$ with His-PRKAR1a $(50 \mathrm{nM})$ or with blocking buffer in the absence of PRKAR1a, and then incubated with Myc-HK2 (32 nM) in blocking buffer or with blocking buffer without HK2 for $2 \mathrm{~h}$. GST-GSK3 $\beta$ or blocking buffer without GSK3 $\beta$ was then added for $2 \mathrm{~h}$. GSK3 $\beta$ binding was detected with anti-GST-HRP-conjugated antibody, and an HRP-catalyzed reaction with a chromogenic substrate solution. Left panel: binding curves were generated as in a (comparison of fits with $p<0.0001)$. Right panel: binding curve after increasing concentrations of G6P as described in a. Nickel-coated plates were successively incubated with His-PRKAR1a ( $50 \mathrm{nM}$ ) overnight, HK2-Myc ( $32 \mathrm{nM})$ for $2 \mathrm{~h}$ and then GST-GSK3 $(32 \mathrm{nM}$ ) for $2 \mathrm{~h}$. Right panel: results are the mean \pm SEM of four independent experiments. panel one-way anova $p<0.0001$.

Fig. 15b). Interestingly, dehydroepiandrosterone (DHEA), which inhibits glucose-6-phosphate dehydrogenase (G6PDH) and the first step of the PPP (Fig. 5a), did not inhibit GSK3 $\beta$ phosphorylation (Fig. 5b), suggesting that G6P does not sufficiently accumulate if only the first step of the PPP is inhibited. Consistently, we found accumulation of G6P in the cells only after 6-AN treatment and not after DHEA treatment (Fig. 5c). To further corroborate these pharmacological results, we used A549 cells expressing doxycycline (DOX)-induced shRNA targeting G6PDH, PGI or 6PGDH. First, we found that both the pentose phosphate pathway (PPP) and glycolysis were inhibited by either 6-AN or 6PGDH knockdown (supplementary Fig. 10a), consistent with inhibition of PGI and the accumulation of G6P. Second, and as expected PGI knockdown decreased secreted lactate, but the secreted lactate was also decreased by $6 \mathrm{PGDH}$ knockdown and not by G6PD knockdown further supporting the notion that 6PGDH deficiency via 6-PG accumulation inhibits PGI (Supplementary Fig. 10b). Consistent with the pharmacological results, only the knockdown of 6PGDH inhibited the phosphorylation of GSK3 $\beta$, like 6AN treatment (Fig. 5d). Furthermore, the same as with 6-AN, 6PGDH deficiency and not PGI deficiency induced the accumulation of both 6PG (Fig. 5e) and G6P (Fig. 5f).

Since NRF2 expression is elevated in A549 cells because of a lack of functional KEAP1, NRF2 protein stability is controlled in these cells by GSK3 phosphorylation in a Keap1-independent manner ${ }^{36}$. Consistently, we found that the knockdown of HK2 in A549 cells decreased the phosphorylation of GSK3 $\alpha$ and GSK3 $\beta$ with concomitant decrease in MCL1 and NRF2 protein levels (Supplementary Fig. 11). Thus, it is expected that NRF2 protein levels would be decreased upon depletion of 6-PGDH. Indeed, we found that following the knockdown of 6-PGDH, NRF2 protein levels declined (Fig. 5g).

Collectively, these results show that HK2 acts as a scaffold that brings together PKA and its substrate, GSK3, to facilitate the phosphorylation of GSK3. As depicted in Supplementary Fig. 12, upon accumulation of G6P or 2-DG6P, which induces an allosteric conformational change in HK2, GSK3 is released and subjected to dephosphorylation by PP2A. We concluded that HK2 inhibits GSK3 activity by sequestration and by facilitating its phosphorylation by PKA as was shown for other two AKAPs. Both AKAP200 and GSK3 $\beta$ interacting protein (GSKIP) were shown to interact with both GSK3 $\beta$ and PKA to facilitate the phosphorylation of GSK3 $\beta$ by PKA ${ }^{29,37,38}$ (see Discussion).

Systemic HK2 deletion in a highly metastatic mouse model of breast cancer decreased metastasis to the lung. In the MMTVPyMT mouse model of breast cancer metastasis, in which the deletion of SNAIL impairs metastasis ${ }^{39}$, we found that HK2 is induced with concomitant induction of SNAIL (Fig. 6a). Since SNAIL is an established target of GSK3 and since HK2 was implicated in breast cancer metastasis ${ }^{40}$, we examined whether HK2 deletion could inhibit breast cancer metastasis, and whether it is dependent on SNAIL. We first wanted to determine if systemic deletion of HK2 after primary breast tumor onset that emulates drug therapy could inhibit breast cancer metastasis. Therefore, we crossed the MMTV-PyMT mice with $H K 2^{f f f}$; UBC$C R E^{E R T 2}$ mice to enable systemic deletion of HK2 (Fig. 6b). Once a primary breast tumor was detected by palpation in experimental $M M T V-P y M T$; HK2 $2^{f f f}$ U UBC-Cre $e^{E R T 2}$ mice and control MMTV$P y M T ; H K 2^{f / f}$ mice, the mice were injected with tamoxifen for 7 consecutive days to systemically delete HK2 in the experimental $M M T V-P y M T ; H K 2 f / f ; U B C-C r e^{E R T 2}$ mice (Fig. 6b). Systemic HK2 deletion increased the time required to reach endpoint (when a tumor reached $\sim 2 \mathrm{~cm}$ in diameter) (Fig. $6 \mathrm{c}$ ). At the tumor endpoint, the mice were euthanized, and the lungs were analyzed for metastases. As shown in Fig. 6d, lung metastatic lesions were markedly decreased by the systemic deletion of HK2. To determine whether the effect of HK2 on metastasis is cell autonomous, mammary epithelial cells were isolated from the breast tumors of donor $M M T V-P y M T ; H K 2^{\mathrm{f} / \mathrm{f}}$ mice and established in tissue culture. The cells were infected with GFP-Cre adenovirus to delete HK2, or GFP adenovirus as a control. The cells were transplanted into the mammary fat pad of recipient NOG mice and followed until endpoint. HK2 deletion significantly decreased metastatic lung lesions (Fig. 6e). To further determine the cell autonomous effect of HK2 on metastasis, we generated MMTV-PyMT;Hk $2^{f /}$

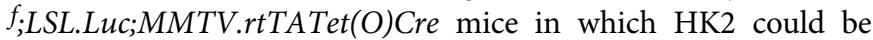
specifically deleted in the mammary gland immediately after tumor onset by exposing the mice to doxcycyline diet (Fig. 6f), and found a marked reduction in the metastatic lesions in the lungs. Thus, the effect of HK2 on metastasis is, at least in part, cell autonomous.

HK2 deletion decreased the expression of epithelial mesenchymal transition (EMT) genes and SNAIL protein abundance. We analyzed the primary tumors with single-cell RNA sequencing (scRNA-seq). We adopted Drop-seq technology for scRNA-seq as previously described ${ }^{41-43}$. We sequenced 28,417 cells from 15 biological replicates of primary tumors derived from $M M T V$ PyMT;HK2ff; $U B C$-Cre $e^{E R T 2}$ mice with and without systemic HK2 deletion (seven replicates and eight replicates, respectively). We found 25 clusters and identified 9 clusters $(0,3,5,9,10,11,14,15$, and 18) within the primary tumor based on the expression of PyMT 

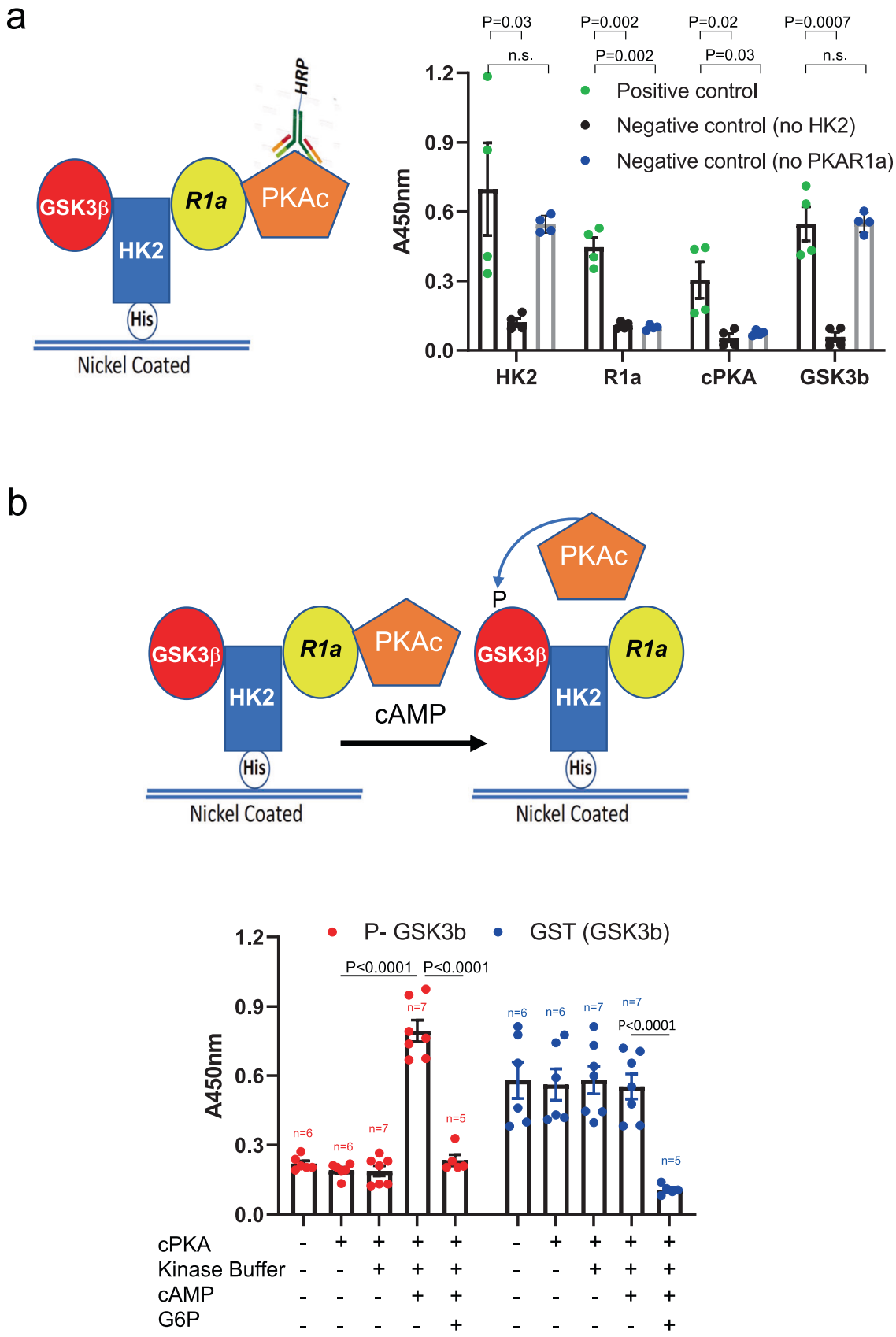

Fig. 4 HK2-GSK3 $\beta-R 1 a$ tertiary complex binds PKA catalytic subunit and promotes GSK3 $\beta$ phosphorylation. a Nickel-coated plates were incubated overnight at $4^{\circ} \mathrm{C}$ with His-HK2 (50 nM) and then successively incubated with Myc-PRKAR1 $\alpha(32 \mathrm{nM})$, PKAc (20 nM), and GST-GSK3 $\beta$ (32 nM). For the negative control experiments, His-HK2 or Myc-PRKAR1 $\alpha$ were omitted. Once all proteins are bound, antibodies against HK2, PRKAR1 $\alpha$, PKAc, or GSK3 $\beta$ are added for overnight incubation and detection is carried out after incubation with HRP-conjugated anti-rabbit or mouse IgG as described in Methods. Results are the mean \pm SEM of four independent experiments. b Nickel-coated plates were incubated overnight at $4{ }^{\circ} \mathrm{C}$ with $\mathrm{His}-\mathrm{HK} 2(50 \mathrm{nM})$ and then successively incubated with Myc-PRKAR1 $\alpha(32 \mathrm{nM})$, PKAc $(20 \mathrm{nM})$ and GST-GSK3 $3(32 \mathrm{nM})$. Kinase buffer in the presence or absence of cAMP is added to appropriate wells and P-GSK3 $\beta$ antibody is added overnight, and then detected by incubation with HRP-conjugated anti-rabbit IgG. Bound total GSK3 $\beta$ is detected with anti-GST-HRP-conjugated antibody. Both detections were revealed by HRP-catalyzed reaction with a chromogenic substrate solution. For G6P inhibition, G6P was added 30 min before the end of the incubation with GST-GSK3 $\beta$. Results are the mean \pm SEM of five independent experiments as depicted by $n$ for each column. One-way ANOVA was used to calculate significance. Source data are provided as Source Data file.

(Fig. 7a, Supplementary Fig. 13a, b, and Supplementary Data 1). Interestingly, when we had a close look at two adjacent clusters; cluster 14, which expresses the highest levels of epithelial markers, and cluster 15, which expresses the highest levels of mesenchymal markers, we found changes in the expression of SNAIL target genes by the deletion of HK2 (Supplementary Fig. 13c). Cluster 14 exhibited high expression of the epithelial markers including E-cadherin (Cdh1), Claudin-1 (Cldn1), and Desmoplakin (Dsp), which are known to be repressed by SNAIL $^{44-46}$. Cluster 15 expresses the highest level of genes that promote EMT and are known SNAIL targets (vimentin (Vim), Matrix metaloproteinase 2 (Mmp2), secreted protein acidic and cysteine rich (Sparc), and Transgelin (Tagln) (Supplementary Data 1 and Supplementary Data 2). Interestingly, the systemic deletion of HK2 markedly reduced SNAIL target genes in Cluster 15 and increased epithelial genes in Cluster 14 in comparison with their levels in the control 

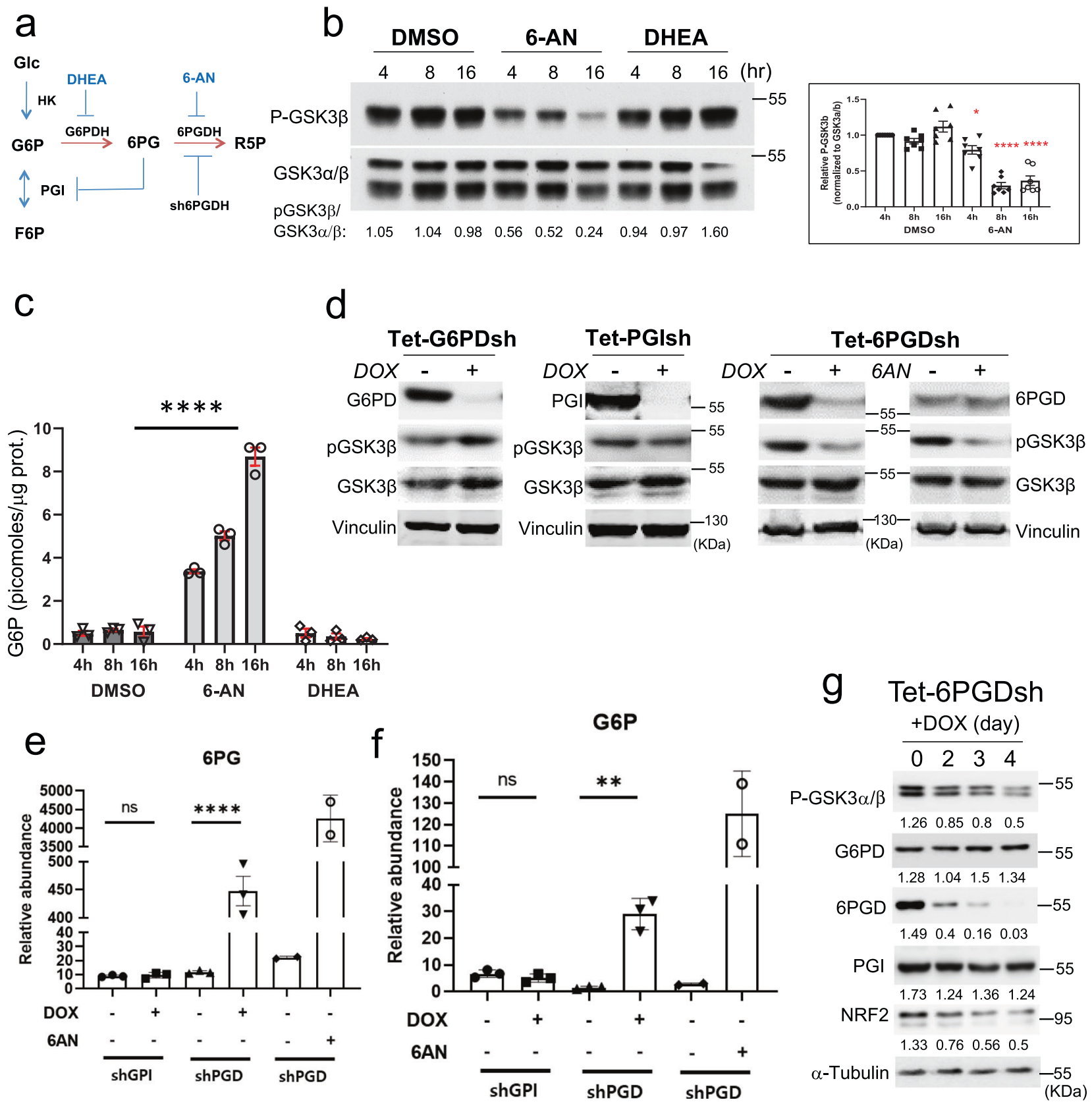

Fig. 5 Evidence that intracellular G6P accumulation inhibits GSK3 phosphorylation. a Schematic showing the effect of DHEA, 6-AN, and the knockdown of 6PGDH on the PPP and glycolysis. $\mathbf{b}$ Left panel: Hela cells were treated with either DMSO, 6-AN, or DHEA. At the indicated time points, cells were harvested for immunoblotting using anti-p-GSK3 $\beta$ and anti-GSK3 $\alpha / \beta$. (representative immunoblot is shown). Right panel: quantifications of the effect of $6 \mathrm{AN}$ on GSK3 $\beta$ phosphorylation. Results are the mean \pm SEM of seven independent immunoblots and data analyzed with Dunnett's multiple comparisons test. ${ }^{\star} p=0.0386,{ }^{\star \star \star \star} p<0.0001$. c Intracellular levels of G6P in control (DMSO treated), $200 \mu \mathrm{M} 6$ 6-AN treated, and $200 \mu \mathrm{M}$ DHEA treated cells at different time points after treatment. Results are the mean \pm SEM of three independent experiments in triplicate. Results are the mean \pm SEM of three independent experiments in triplicate. ${ }^{\star \star \star \star} p<0.0001$ versus DMSO; two-sided unpaired $t$-test. d A549 cells stably expressing each shRNA in the tet-on system were treated with doxycycline (DOX, $0.2 \mu \mathrm{g} / \mathrm{ml}$ ) for 6 days, cells were harvested and analyzed by immunoblotting. A549 cells expressing inducible 6PGD shRNA (Tet-6PGDsh) were also treated with 6-AN for $16 \mathrm{~h}$ in the absence of DOX. Immunoblots are representative of three experiments. e Cells were treated and isotopically labeled as in d, and 6PG level was measured after GPI and 6PGD knockdown or after treatment with 6-AN. Relative abundance of intracellular $2 x^{13} \mathrm{C} 6 \mathrm{PG}(\mathrm{M}+2)$ after $25 \mathrm{mM}\left[1,2-{ }^{13} \mathrm{C}_{2}\right]$-glucose labeling for $4 \mathrm{~h}$ is shown. Results are the mean $\pm \mathrm{SEM}$ of three independent experiments (two independent experiments for the 6-AN treatment). $p$-values were calculated using two-tailed unpaired $t$-test; ns $p=0.6725$;

${ }^{\star \star \star \star} p<0.0001$. $\mathbf{f}$ Experiment was done as in $\mathbf{e}$, except that the relative of intracellular $2 x^{13} \mathrm{C} G 6 \mathrm{P}(M+2)$ was measured. Results are the mean $\pm \mathrm{SEM}$ of three independent experiments (two independent experiments for the 6-AN treatment). $p$-values were calculated using two-tailed unpaired $t$-test ns $p=0.2442 ;{ }^{\star \star} p<0.01(p=0.0013)$. g A549 cells expressing inducible 6PGD shRNA (Tet-6PGDsh) were exposed to DOX and pGSK3 and NRF2 levels were followed for 4 days after DOX addition (numbers indicate level relative to tubulin). Immunoblot is a representative of three independent experiments. Uncropped blots are provided as a Supplementary Fig. 16. Source data are provided as a Source Data file. 

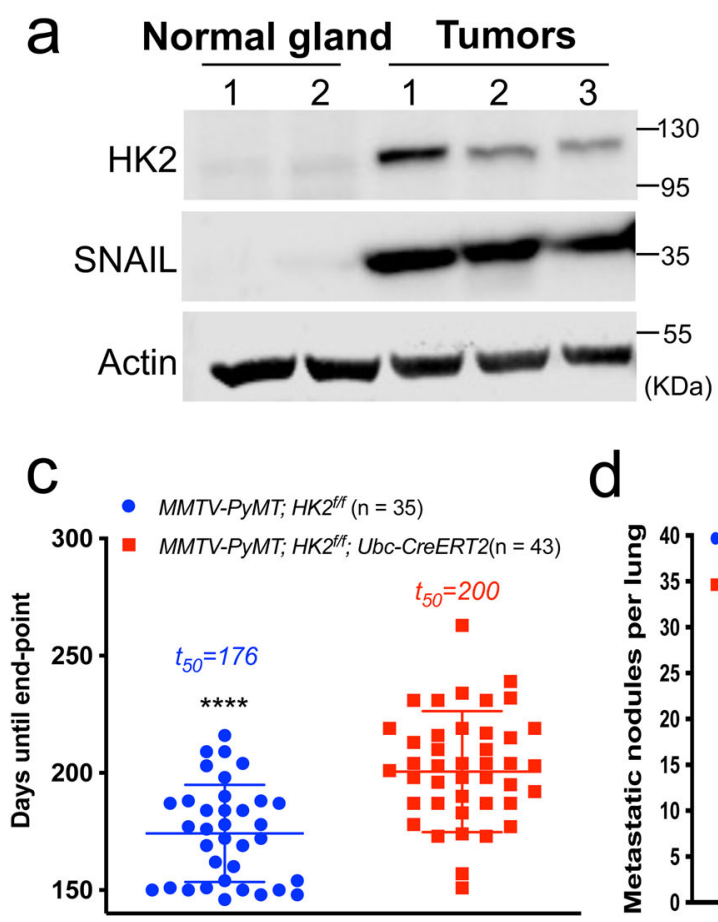

f

MMTVPYMT;Hk2ff; $\quad$ MMTVPYMT; LSL.LuC;MMTV.rtTATTEt(O)Cre LSL.Luc;MMTV.rtTATTEt(O)Cre

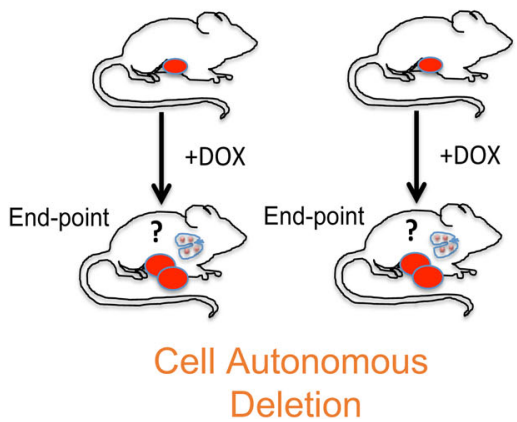

b

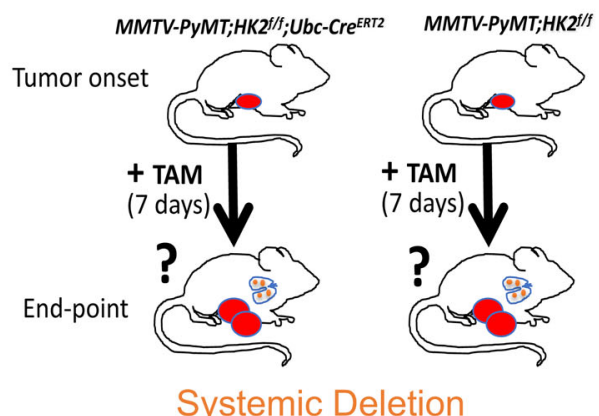

e
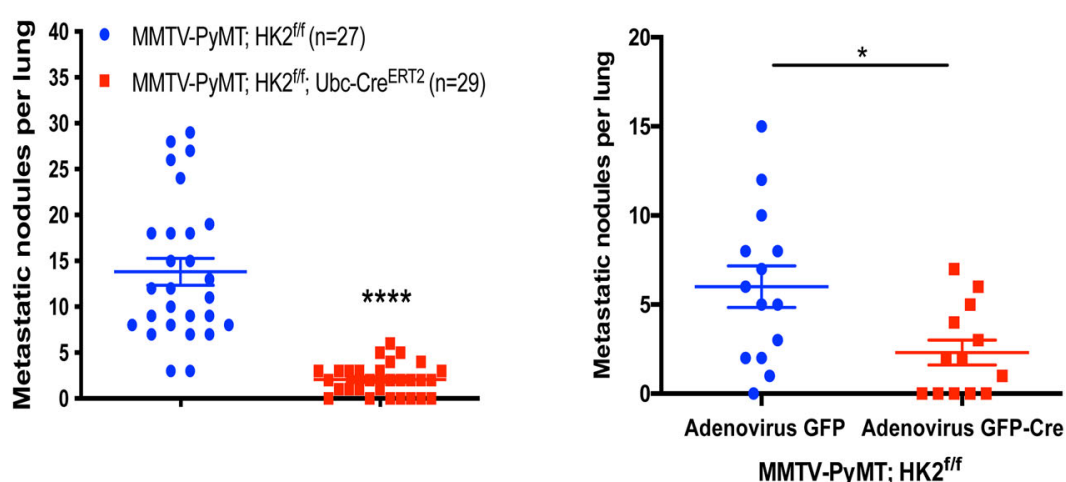

- MMTV-PYMT; LSL.Luc;MMTV.rtTATTet(O)Cre

- MMTV-PYMT; HK2 ${ }^{f f}$;LSL.Luc;MMTV.rtTATTet(O)Cre

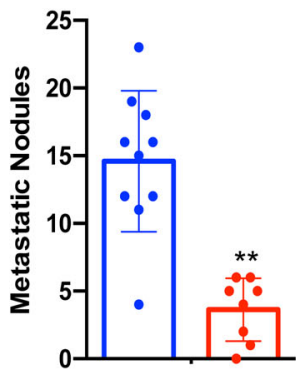

Fig. 6 Systemic and cell autonomous deletion of HK2 inhibits metastasis to the lung in MMTV-PyMT mice. a Immunoblot image of HK2 and SNAIL protein levels in tissue samples collected from normal mammary glands from two different female mice and primary mammary gland tumors from three different female mice. b Schematic illustration depicting the experimental approach for systemic deletion of HK2 in MMTV-PyMT mouse model. Once a primary tumor was palpable, tamoxifen (TAM) was injected for 7 consecutive days in MMTV-PyMT; HK2f/f; UBC-Cre ${ }^{E R T 2}$ and MMTV-PyMT; HK2f/f mice. At endpoint, mice were euthanized and lung metastasis was quantified. c Tumor endpoint analysis in MMTV-PyMT; HK2f/f; UBC-CreERT2 and MMTV-PyMT; $H K 2^{f / f}$ mice with TAM injection at tumor onset. Results are the mean $\pm \mathrm{SEM}$; ${ }^{\star \star \star \star} p<0.0001$ or (or $p=5.48 \mathrm{E}-06$ ) using unpaired two-tailed $t$-test. d Incidence of metastatic lesions in the lungs. When tumors reached endpoint, the mice were euthanized, and metastatic lesions in the lungs were quantified. Results are the mean $\pm \mathrm{SEM}$; ${ }^{\star \star \star \star} p<0.0001$ (or $p=7.2186 \mathrm{E}-11$ ) using unpaired two-tailed $t$-test. e Cell-autonomous deletion of HK2 impairs lung metastasis. Isolated MMTV-PyMT;HK2f/f mammary tumor cells were treated with GFP-Cre adenovirus to delete HK2 or GFP adenovirus as a control. After $72 \mathrm{~h}$, the cells were transplanted into the mammary fat pads of recipient immunodeficient NOG mice. At the endpoint, mice were euthanized, and lung metastatic lesions were quantified. The results are the mean $\pm \mathrm{SEM} ;{ }^{*} p=0.013$ using unpaired two-tailed $t$-test with $(n=13$ biologically independent animals with MMTV-PyMT;HK2f/f GFP-Cre adenovirus cells and $n=14$ biologically independent animals with MMTV-PyMT;HK2f/f GFP adenovirus). $\mathbf{f} U$ pper panel: schematic showing experimental design. MMTV-PyMT;HK2f/f;LSL.Luc;MMTV.rtTATet(O)Cre and control MMTV-PyMT;LSL.Luc;MMTV.rtTATet(O)Cre mice were subjected to DOX diet after tumor onset and metastasis was quantified at endpoint. Bottom panel: quantification of metastasis to the lung. The results are the mean $\pm \mathrm{SEM} ;{ }^{\star \star} p=0.0038$ using one-way. ANOVA. ( $n=10$ for MMTV-PyMT;LSL.Luc;MMTV.rtTA;Tet(O)Cre mice and $n=8$ for MMTVPyMT;HK2fff;LSL.Luc;MMTV.rtTA;Tet(O)Cre mice). Uncropped blots are provided as a Supplementary Fig. 16. Source data are provided as a Source Data file.

samples (Fig. 7b and c). These results suggest that the loss of HK2 in primary tumors impaired the expression of SNAIL-regulated targets important for EMT and metastasis.

EMT is important for breast cancer metastasis, and the deletion of SNAIL in the mammary gland of MMTV-PyMT mice was shown to inhibit metastasis to the lung ${ }^{39,47}$. Therefore, the results raised the possibility that the deletion of HK2 could affect metastasis by impairing SNAIL activity to mediate EMT. Indeed, we found that SNAIL protein levels in the tumors were markedly reduced after HK2 deletion (Fig. 7d). To determine if the effect of systemic HK2 deletion on SNAIL is cell autonomous, we analyzed primary tumors in the cell autonomous mouse model described in Fig. 6f. As shown in Fig. 7e, cell autonomous HK2 deletion in the mammary gland decreased p-GSK3 $\beta$, with concomitant 

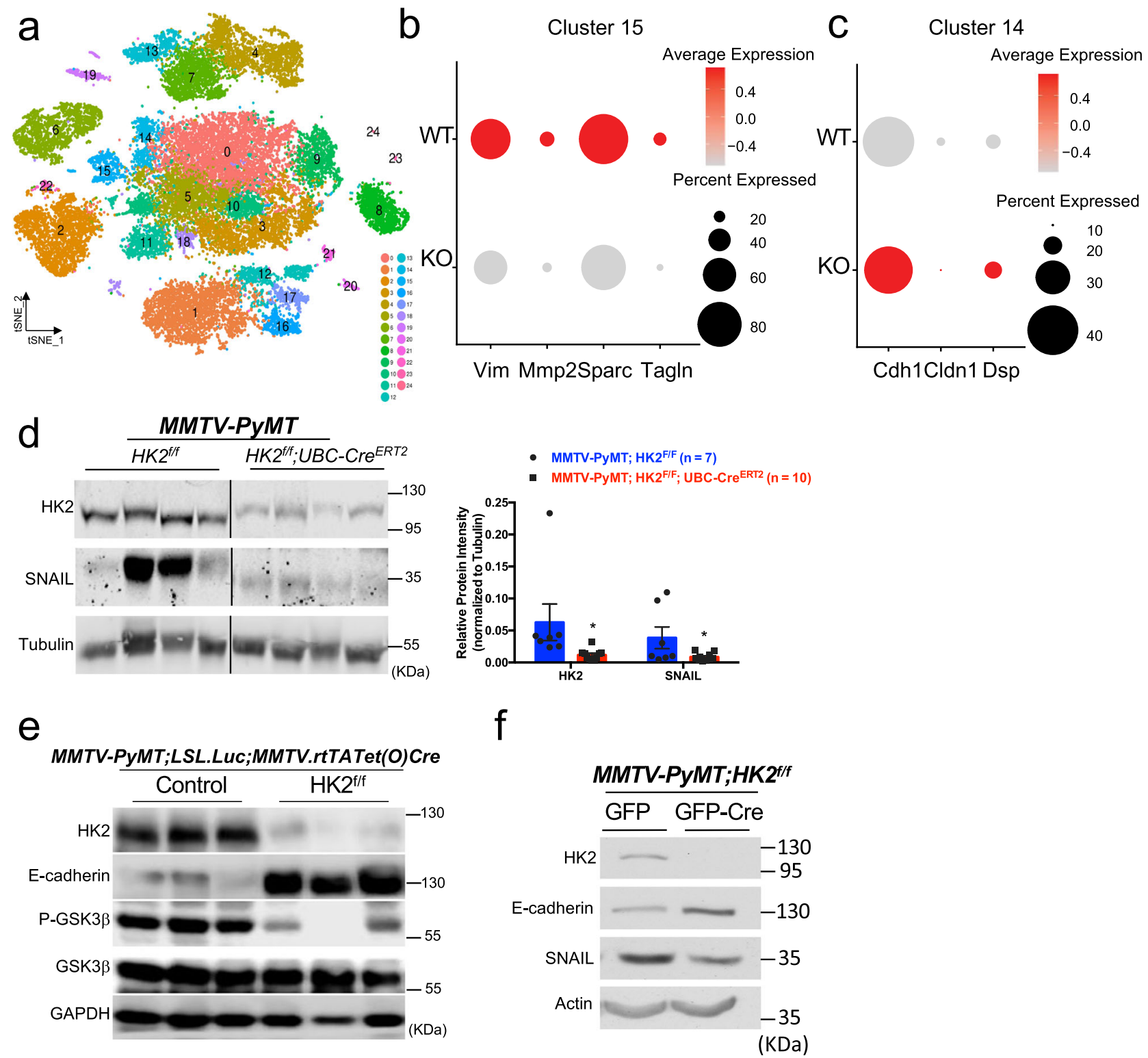

Fig. 7 The effect of HK2 deletion on specific SNAIL target gene expression in epithelial and mesenchymal cell clusters and SNAIL protein levels in the primary tumors. a Single-cell RNA sequencing and clustering of primary tumor cells derived from tumors at end-point of MMTV-PyMT;HK2f/f ( $n=7)$ and MMTV-PyMT;HK2f/f;UBC-CreERT2 $(n=8)$ mice after TAM exposure. t-Distributed Stochastic Neighbor Embedding (tSNE) is shown. The color-coded clusters are grouped together by similar gene expression. Twenty-five clusters including nine primary tumor PyMT-expressing clusters were identified. b Dot plot showing the expression of SNAIL targets important for EMT and metastasis (Vim, Mmp2, Sparc, Tagln) in Cluster 15 from WT and KO (MMTVPyMT;HK2 $2^{f / f}$ and MMTV-PyMT;HK2 $\left.{ }^{f / f} ; U B C-C r e{ }^{E R T 2}\right)$ tumors after TAM exposure at tumor onset. High RNA expression is indicated by a dark red color. c Dot plot showing the expression epithelial markers such as E-cadherin (Cdh1), Claudin-1 (Cldn1), and Desmoplakin (DSP) in Cluster 14 from WT and KO (MMTV-PyMT;HK2 $2^{f / f}$ and MMTV-PyMT;HK2f/f;UBC-Cre ERT2 tumors after TAM exposure at tumor onset). A high RNA expression is indicated by a dark red color. d Left: immunoblot image of HK2 and SNAIL protein levels in tissue samples collected from primary mammary gland tumors at end-point after exposure to TAM at tumor onset, in MMTV-PyMT;HK2f/f and MMTV-PyMT;HK2f/f;UBC-Cre ERT2 mice. Right: quantification of HK2 and SNAIL protein levels, $M M T V-P y M T ; H K 2^{f / f}$ ( $n=7$ tumors from four different mice), MMTV-PyMT;HK2f/f;UBC-Cre ${ }^{E R T 2}$ ( $n=10$ tumors from six different mice). Results are the mean \pm SEM. ${ }^{*} p=0.048$ versus MMTV-PyMT;HK2f/f; unpaired two-tailed $t$-test. e Immunoblot image of HK2, pGSK3b, GSK3 $\beta$, E-cadherin, and SNAIL protein levels in primary mammary tumors at end-point derived from MMTV-PyMT;LSL.LuC;MMTV.rtTATet(O)Cre control mice $(n=3)$ or MMTV-

PyMT;HK2 ${ }^{f / f} ;$ LSL.Luc;MMTV.rtTATet $(O)$ Cre mice $(n=3)$ subjected to DOX diet after tumor onset. f Representative immunoblot image of HK2, E-cadherin, and SNAIL protein levels in protein extracts from cells isolated from tumors in MMTV-PyMT;HK2f/f mice after infection with adenovirus expressing either GFP or GFP-Cre. Similar results obtained in three independent experiments. Uncropped blots are provided as a Supplementary Fig. 16. Source data are provided as a Source Data file.

increase in E-cadherin, in the primary tumors. Finally, when cells were isolated from the primary tumors of $M M T V-P y M T ; H K 2 f / f$ mice and HK2 was deleted by adenovirus expressing Cre, we found that the SNAIL protein level was decreased and a concomitant increase in the E-cadherin protein level (Fig. 7f). Taken together, these results indicate that HK2 deletion reduced SNAIL protein level and leading to a decrease in its transcriptional activity important for EMT. 

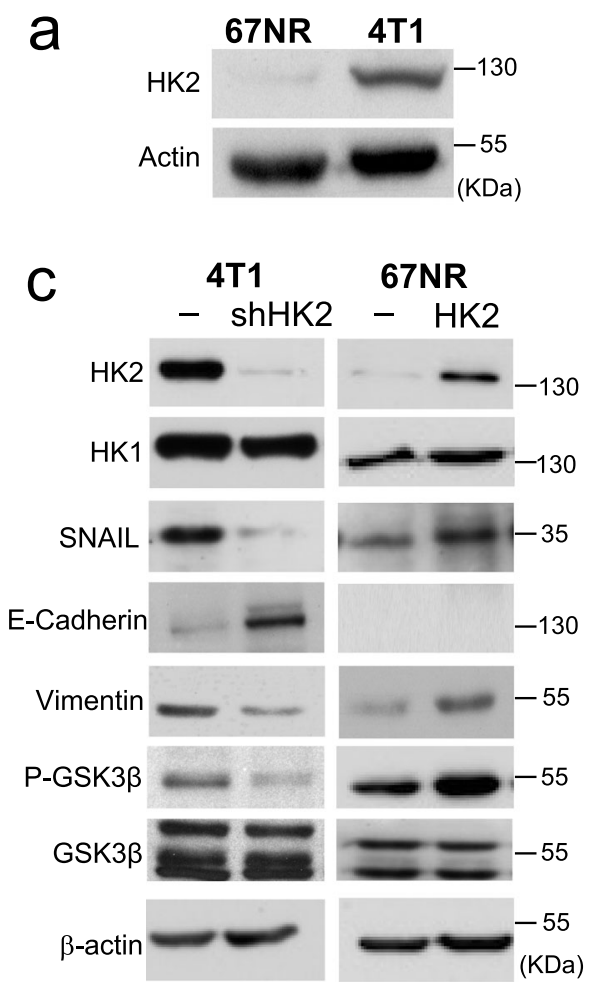

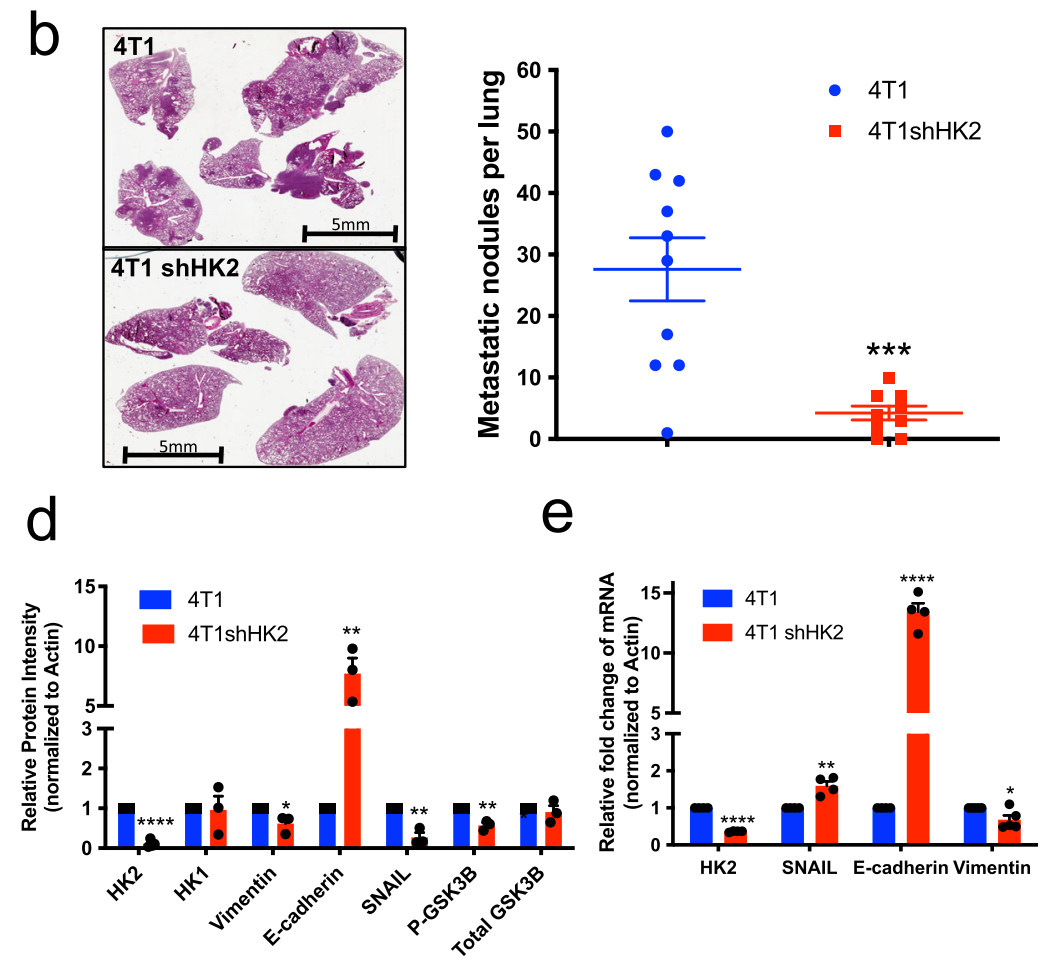

Fig. 8 HK2 silencing in 4T1 cells inhibits metastasis to the lung, decreases SNAIL protein level and EMT gene expression. a Immunoblot image, representative of 3 independent experiments, showing HK2 levels in two isogenic breast cancer cell lines: 67NR (a non-metastatic line) and 4T1 (a highly metastatic line). b Left: representative images showing H\&E staining of lung sections after orthotopic transplantation of 4T1 or 4T1shHK2 cells into Balb/cj mice. Scale bar: $5 \mathrm{~mm}$. Right: quantification of lung metastatic lesions ( $4 \mathrm{~T} 1$ transplantation, $n=10 ; 4 \mathrm{~T} 1$ shHK2 transplantation, $n=9$ ) at endpoint. Results are the mean $\pm \mathrm{SEM} ;{ }^{\star \star \star} p=0.0006$ analyzed by an unpaired two-tailed $t$-test. c A representative immunoblot image showing the effect of HK2 silencing in $4 T 1$ cells and overexpression of HK2 in 67NR cells on SNAIL and E-cadherin protein levels and GSK3 $\beta$ phosphorylation $n=3$ (three independent experiments). d Quantification of protein levels after HK2 silencing in 4T1 cells. Results are the mean \pm SEM of three independent experiments. ${ }^{\star} p<0.05$ versus 4T1 (HK2 $p=1.29 \mathrm{E}-06, \mathrm{HK} 1 p=0.91, \operatorname{Vim} p=0.043$, E-cad $p=0.0064$, SNAIL $p=0.0033, \mathrm{P}-\mathrm{GSK} 3 \mathrm{~B} p=0.0039$, Total GSK3B $p=0.59$ ); unpaired two-tailed $t$-test. e Quantitative RT-PCR analysis measuring relative mRNA levels in 4 T1 and 4T1shHK2 cells. Results are the mean \pm SEM ( $n=4$ biologically independent experiments). ${ }^{*} p<0.03$ versus 4 T1 (HK2 $p=5.7 \mathrm{E}-10$, SNAIL $p=0.0023$, E-cad $p=2.34 \mathrm{E}-06$, Vim $p=0.026$ ); unpaired twotailed $t$-test. Uncropped blots are provided as a (Supplementary Fig. 16). Source data are provided as a Source Data file.

Increased HK2 expression correlates with increased metastatic potential. To further investigate the cell autonomous role of HK2 in metastasis, we utilized two isogenic mammary tumor cell lines (67NR and 4T1) that, when implanted into the mammary gland of mice, display different metastatic potential ${ }^{48}$. Both cell lines could form mammary tumors within a month. However, the 67NR cells only forms primary tumors with no metastasis, whereas the 4T1 cells forms primary tumor with high incidence of metastasis to the lung. When HK2 protein levels were analyzed, the non-metastatic cell line 67NR exhibited markedly lower levels when compared to the highly metastatic 4T1 cell line (Fig. 8a). As a result, this enabled us to manipulate the level of HK2 expression in these cell lines to determine whether HK2 plays a cell autonomous role in the metastatic potential of these cell lines. Therefore, we silenced HK2 in 4T1 cells (4T1shHK2) and overexpressed HK2 in 67NR cells (67NR HK2) (Supplementary Fig. 14a). The knockdown of HK2 in 4T1 cells decreased transwell migration, and invasion (Supplementary Fig. 14b, d) while the overexpression of WT HK2 in 67NR cells increased migration (Supplementary Fig. 14b, c). Interestingly, even overexpression of kinase inactive HK2DA mutant in 67NR cells was able to increase migration (Supplementary Fig. 14c), suggesting that, at least in these cells, the scaffolding activity of HK2 is predominant in promoting migration. Thus, overall, HK2 level appears to correlate with the metastatic potential of these cell lines. Next, we assessed the effect of HK2 on the metastasis of
4T1 cells in vivo. $4 \mathrm{~T} 1$ or $4 \mathrm{~T} 1$ shHK2 cells were injected orthotopically into the fourth mammary fat pad of syngeneic mice. At endpoint, when primary tumors reached the same size, the mice were euthanized, and the lungs were analyzed for lung metastases. The knockdown of HK2 significantly decreased the number of lung metastases. The control 4T1 tumors had an average of 28 lung metastases whereas the mice with $4 \mathrm{~T} 1$ shHK2 tumors had an average of 4 lung metastases (Fig. 8b).

HK2 silencing in 4T1 cells inhibits SNAIL protein stability and nuclear localization in a GSK3-dependent manner, and SNAIL resistant to GSK3 phosphorylation restores metastasis of HK2deficient 4T1 cells. As SNAIL protein level was shown to be regulated by GSK3 phosphorylation, targeting it for proteasomal degradation $^{20}$, and because SNAIL protein level and GSK3 $\beta$ phosphorylation are decreased in the primary tumors (Fig. 7d-f), we determined whether HK2 affects the level of SNAIL via GSK3. We employed the two isogenic breast cancer cell lines, 4T1 and $67 N R$. Consistent with the results obtained with the primary MMTV-PyMT tumors (Fig. 7d-f), SNAIL protein levels were decreased by knocking down HK2 in 4T1 cells, with a concomitant decrease in Vimentin and increase in E-cadherin at both the protein and mRNA levels (Fig. 8a-e). Interestingly, the mRNA level of SNAIL (Fig. 8e) did not correlate with SNAIL protein levels (Fig. 8c, d), indicating that SNAIL protein stability 


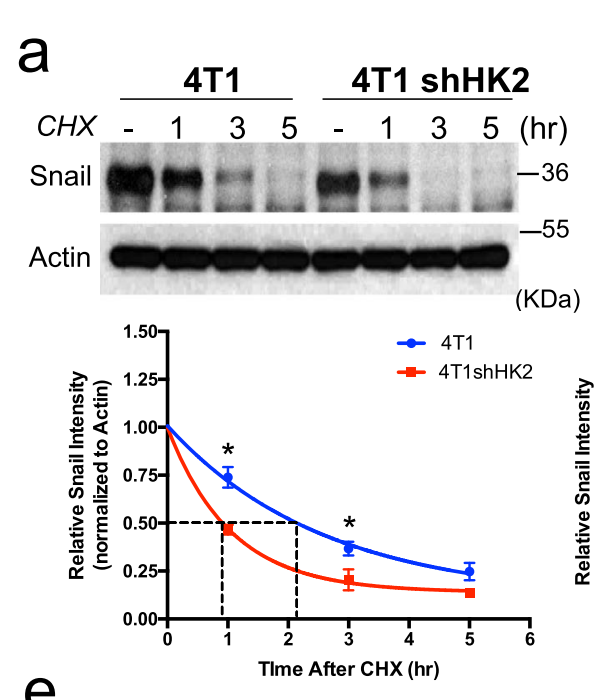

e

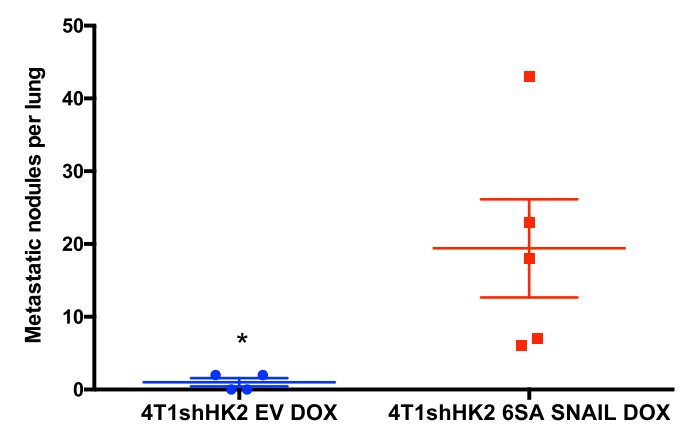

b

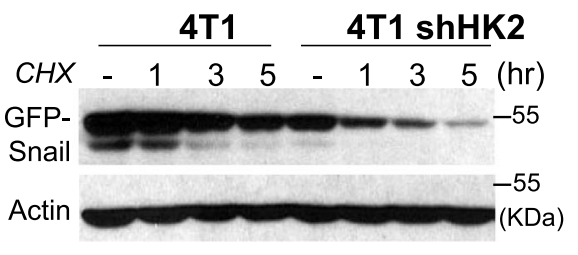

C

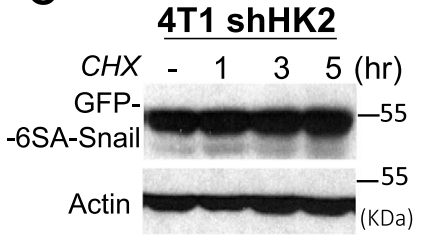

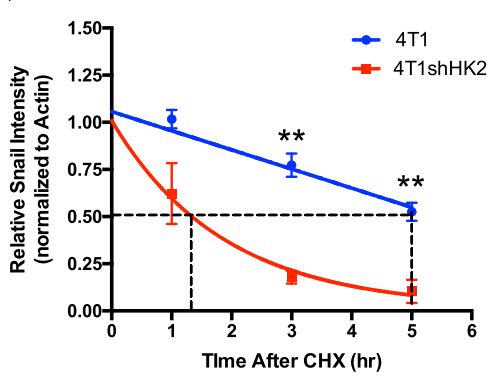
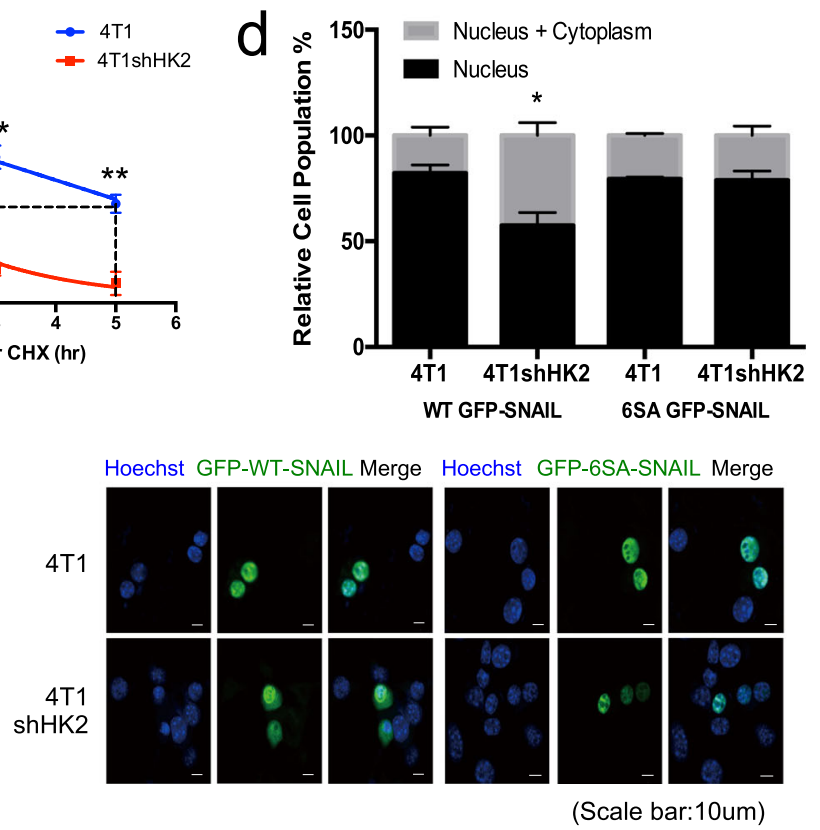

Fig. 9 HK2 silencing in 4T1 cells inhibits SNAIL protein stability and nuclear localization in a GSK3-dependent manner, and SNAIL resistant to GSK3 phosphorylation restores metastasis of HK2-deficient 4T1 cells. a Protein stability of SNAIL in 4T1 and 4T1shHK2 cells as measured after exposure to cycloheximide $(\mathrm{CHX})$. Upper: representative immunoblot image. Bottom: plot showing SNAIL protein half-life after quantification relative to $\beta$-actin in three independent experiments. The half-life results are the mean $\pm \mathrm{SEM}$. ${ }^{\star} p=0.0104$ in $1 \mathrm{~h},{ }^{\star} p=0.0237$ in $3 \mathrm{~h}$ versus $4 \mathrm{T1}$; two-sided unpaired $t$-test. $\mathbf{b}$ Protein stability of transiently expressed GFP-tagged SNAIL in $4 \mathrm{~T} 1$ and $4 \mathrm{~T} 1 \mathrm{shHK} 2$ cells as measured after exposure to cycloheximide (CHX). Upper: representative immunoblot image. Bottom: plot showing GFP-SNAIL protein half-life after quantification relative to $\beta$-actin in three independent experiments. The half-life results are the mean \pm SEM. ${ }^{\star \star} p=0.0011$ in $3 \mathrm{~h},{ }^{\star \star} p=0.0058$ in $5 \mathrm{~h}$ versus $4 \mathrm{T1}$; two-sided unpaired $t$-test. c Immunoblot image showing the level of transiently expressed GFP-tagged 6SA-SNAIL mutant in 4T1shHK2 after exposure to cycloheximide over a 5-h time course in three independent experiments. d GFP-SNAIL and GFP-6SA-SNAIL were transiently expressed in 4T1 and 4T1shHK2 cells. After fixation of the cells, the localization of SNAIL (green) and nuclei (blue; Hoechst 33342) was examined under a fluorescence microscope and quantified (bottom). The bar graph represents the relative GFP-SNAIL localization in the cytoplasm versus in the nucleus in 4T1 and 4T1shHK2 cells in three independent experiments. Each experiment was observed in at least 40 randomly selected fields (x400 magnification). Data represent the mean \pm SEM; Statistical significance of the differences was determined by one-way ANOVA (Bonferroni's method); ${ }^{\star} p=0.02$. e Transient expression of 6SA SNAIL in 4T1shHK2 cells restores metastasis to the lung. 4T1shHK2 cells expressing DOX-inducible empty vector (EV) and 4T1shHK2 cells expressing DOX-inducible 6SA SNAIL were orthotopically implanted in Balb/cj mice (4T1shHK2 EV, $n=4 ; 4 T 1$ shHK2 6SA SNAIL, $n=5$ ) and exposed to DOX for 1 week. At endpoint lung metastatic lesions were quantified. The results are the mean $\pm \mathrm{SEM} ;{ }^{*} p=0.047$ using unpaired two-tailed $t$-test. Uncropped blots are provided as a Supplementary Fig. 16. Source data are provided as a Source Data file.

was impaired by HK2 silencing. We also found that the decrease of SNAIL protein level in 4T1shHK2 cells was associated with a concomitant decrease in GSK3 $\beta$ phosphorylation, whereas the increase in SNAIL protein level in 67NR WTHK2 cells is associated with concomitant increase in GSK3 $\beta$ phosphorylation (Fig. 8c, d). To directly test the possibility that HK2 affects SNAIL protein stability, we analyzed the half-life of SNAIL in 4T1 cells after the knockdown of HK2 and found that the half-life of SNAIL protein was markedly decreased (Fig. 9a). The half-life of ectopically expressed SNAIL-GFP fusion protein was also markedly decreased by the knockdown of HK2 (Fig. 9b), but this was not true for the half-life of 6SA-SNAIL-GFP fusion protein, in which all the serine residues that are phosphorylated by GSK3 were converted alanine residues ${ }^{20}$ (Fig. 9c).
GSK3 $\beta$ not only targets SNAIL for degradation, but also shifts the localization of SNAIL from the nucleus to the cytoplasm ${ }^{20}$. We wanted to determine whether HK2 expression could mediate the localization of SNAIL in a GSK3 $\beta$-dependent manner. We therefore quantified the intracellular localization of WT SNAILGFP fusion protein or mutant 6SA-SNAIL-GFP fusion protein, which is resistant to GSK3 phosphorylation ${ }^{20}$, in 4T1 and 4 T1shHK2 cells. WT SNAIL was mainly localized to the nucleus in the $4 \mathrm{~T} 1$ cells, but its localization shifted to a more cytoplasmic localization in the 4T1shHK2 cells, whereas the SNAIL-6SA mutant remained mostly nuclear in both cell lines (Fig. 9d). Taken together these results strongly demonstrate that HK2 affects SNAIL protein stability and nuclear localization via its effect on GSK3. Furthermore, 2DG treatment, which led to the 
accumulation 2DG6P, as well as 6-AN treatment that leads to accumulation of G6P and activation of GSK3 decreased SNAIL protein levels in $4 \mathrm{~T} 1$ cells (Supplementary Fig. 15 a, b, c). Finally, the same as was shown for HEK293 cells in Fig. 2f, we found that in $4 \mathrm{~T} 1$ cells endogenous HK2 binds endogenous GSK3 only in the presence of glucose and not in the in the presence of 2-DG (Supplementary Fig. 15c).

If the HK2 effect on metastasis is via SNAIL, it is expected that 6SA-SNAIL mutant would restore metastasis in HK2-deficient cells. Since it was reported that only transient SNAIL expression induces metastasis, whereas constitutive expression of SNAIL does not and may impede metastasis ${ }^{39}$, we generated a 4T1shHK2 cell line with doxycycline-inducible 6SA-SNAIL expression. Transient inducible expression of SNAIL-6SA mutant in the $4 \mathrm{~T} 1 \mathrm{shHK} 2$ in mice rescued changes in lung metastasis (Fig. 9e). We concluded that HK2 affects metastasis through its effect on SNAIL protein stability and nuclear localization.

HK2 deficiency impaired global O-GlcNAcylation and specific SNAIL O-GlcNAc modification. It was previously reported that O-linked-N-acetylglucosamine (O-GlcNAc) modification (OGlcNAcylation) is important to breast cancer primary tumor progression and metastasis, and that primary tumor GlcNAcylation levels were found to be increased during mammary tumor progression in MMTV-PyMT mice ${ }^{49}$. Uridine $5^{\prime}$-diphospho-N acetylglucosamine (UDP-GlcNAc), which is transferred to the serine or threonine residues of proteins to yield O-GlcNAcylation, is generated by the hexosamine biosynthetic pathway. Flux in the hexosamine biosynthesis pathway is dependent on G6P, raising the possibility that $\mathrm{HK} 2$ deficiency reduces glycosylation. By using an O-GlcNAc specific antibody on total protein lysates, we found that the systemic deletion of HK2 in MMTV-PyMT mice decreased the total O-GlcNAcylation levels in the primary tumors at endpoint (Fig. 10a). Consistently, the non-metastatic 67NR cells, which express relatively low level of HK2, had less total O-GlcNAcylation when compared to the metastatic 4T1 cells, which express higher level of HK2 (Fig. 10b). Furthermore, the knockdown of HK2 in 4T1 cells decreased total protein O-GlcNAcylation, and overexpression of WT HK2 in 67NR cells increased the total protein O-GlcNAcylation (Fig. 10b). Taken together these results strongly suggest that HK2 deficiency reduces global O-GlcNAcylation. To further interrogate the role of $\mathrm{HK} 2$ in the hexosamine pathway we conducted a metabolic labeling experiment to determine whether HK2 deficiency decreases the flux of glucose to the hexosamine pathway. As shown in Fig. 10c, HK2 deficiency markedly decreased the incorporation of $\mathrm{U}^{13} \mathrm{C}_{6}$ glucose in all UDPGlcNAc isotopomers.

O-GlcNAcylation had been shown to contribute to SNAIL protein stability by blocking GSK3 $\beta$ from serially phosphorylating SNAIL to promote its degradation ${ }^{50}$. O-GlcNAc at Ser112 stabilizes SNAIL by blocking GSK3 $\beta$ from serially phosphorylating at serine 104,107 , and 111 and promoting SNAIL degradation ${ }^{50}$. Therefore, we wanted to examine whether in addition to the non-catalytic effect of HK2 on GSK3 activity, HK2 could affect the glycosylation of SNAIL. To verify whether there are specific changes in O-GlcNAcylation of the SNAIL protein itself occurred, GFPSNAIL was transiently expressed in the $4 \mathrm{~T} 1$ and $4 \mathrm{~T} 1 \mathrm{shHK} 2$ cells. This was followed by immunoprecipitation with anti-O-GlcNAc antibody and immunoblotting with anti-SNAIL antibody (Fig. 10d). The results clearly showed that SNAIL O-GlcNAcylation was diminished by the deficiency of HK2. We concluded that in addition to its non-catalytic activity on GSK3, HK2 catalytic ability can also contribute to the stability and nuclear localization of SNAIL via O-GlcNAcylation (Fig. 10e).

\section{Discussion}

HK2 is markedly induced in cancer cells when compared to normal cells. An increase in HK2 expression and activity is a critical determinant of the accelerated glucose metabolism in cancer cells. We previously documented that HK2 is required for tumorigenesis both in vitro and in vivo ${ }^{4,51,52}$. HK2 expression also correlates with the incidence of breast cancer metastasis to the brain ${ }^{40}$. However, thus far the pro-tumorigenic role of HK2 has been attributed to its metabolic activity as a glucose kinase that converts glucose to glucose 6-phosphate. Here we uncovered an activity of $\mathrm{HK} 2$ independent of its catalytic activity. We showed that HK2 binds to GSK3 as well as the PKA regulatory subunit RIa, and it is conceivable that HK2 thereby facilitates the phosphorylation of GSK3 by PKA. Since these interactions may not require $\mathrm{HK} 2$ catalytic activity, $\mathrm{HK} 2$ may act as purely a scaffold in this scenario. On the other hand, the conversion of glucose to G6P or 2-DG to 2-DG6P by catalytically active hexokinase seems to be required for the diminished phosphorylation of GSK3 and therefore its activation. Binding of G6P or 2-DG6P to $\mathrm{HK} 2$ induces a conformational change that can dissociate GSK3. Indeed, we found that 2-DG disrupted the HK2-GSK3 and HK2-RIa interactions. In addition, we found that following the dissociation of GSK3 by 2-DG, it interacts with PP2A, which facilitates its dephosphorylation and thus its activation.

Our results suggest that $\mathrm{HK} 2$ can function as an A-kinaseanchoring protein (AKAP), a novel moonlighting function for this important glycolytic enzyme that has not previously been described. Two of the AKAPs, AKAP220 and GSKIP, were shown to facilitate GSK3 phosphorylation by anchoring PKA through its interaction with PRKAR2 $29,37,38$, but AKAP220 was also reported to interact with PRKAR ${ }^{38}$. Interestingly, some AKAPs were shown to interact with phosphatases. For instance, AKAP220 was shown to interact with PP1, which could contribute to the regulation of GSK3 phosphorylation ${ }^{38}$. Although we were unable to demonstrate binding of PP2A to HK2, we showed that GSK3 binds PP2A when not sequestered by HK2. That said, we cannot completely exclude PP2A binding to HK2. It is interesting to note that D-AKAP1 interacts with the outer mitochondrial membrane through a hydrophobic motif similar to those of HK1 and $\mathrm{HK} 2^{53}$ and thus could be in close proximity to the mitochondrial HK2. Therefore, we could not completely rule out the possibility that PKA and phosphatases associated with D-AKAP1 could also influence the phosphorylation of GSK3 associated with HK2, although we found that a mitochondrial binding-deficient mutant of HK2 could still exert a similar effect on GSK3. We clearly showed that HK2 binds GSK3 $\beta$ and affects GSK3 $\beta$ phosphorylation in a kinase-independent manner. The yeast two-hybrid screen showed that the amino-terminus domain of RIa, which possess the docking site to AKAPs ${ }^{24}$, is sufficient to bind HK2. The binding of HK2 to RIa was confirmed by coimmunoprecipitation in mammalian cells and together with the inhibition of HK2-mediated GSK3 phosphorylation by pharmacological inhibitors of adenylate cyclase and PKA, the results strongly suggest that HK2 could be a bona-fide AKAP. This is confirmed by the in vitro binding assays with purified proteins that showed unequivocally a direct binding between HK2, GSK $3 \beta$, and RIa to form complexes that are disrupted upon addition of G6P.

All $\sim 100 \mathrm{kDa}$ high-affinity hexokinases are thought to have arisen from gene duplication and tandem ligation events involving a common ancestral $\sim 50 \mathrm{kDa}$ hexokinase ${ }^{23,54}$. Because of this common evolutionary origin, the individual amino- and carboxy-halves of HK2 are highly homologous with each other and with the corresponding hemi domains of HK1. Given their known structural similarities, it is conceivable that both hemi domains could anchor GSK3, PKA, and possibly PP2A (Supplementary Fig. 12). Although 

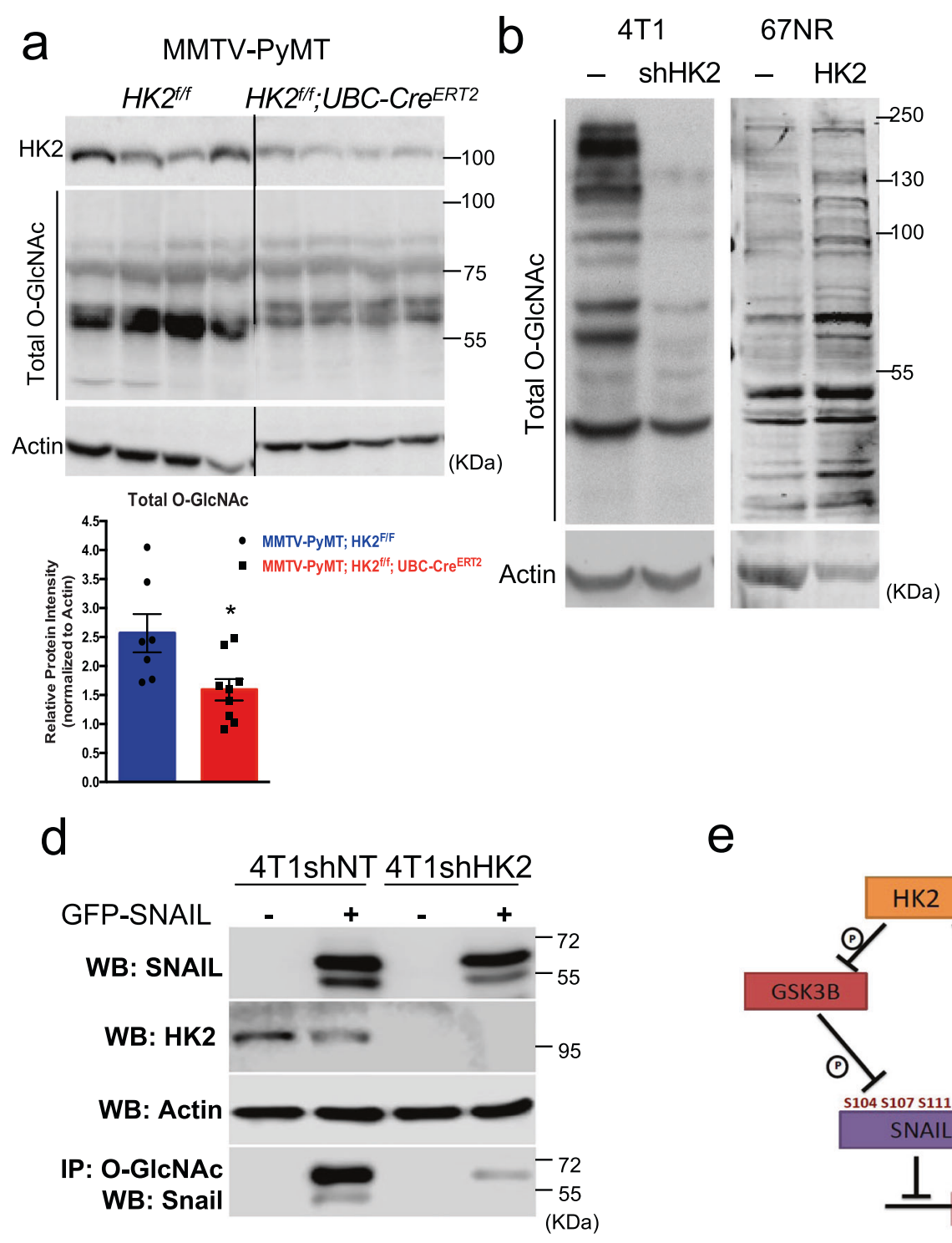

e

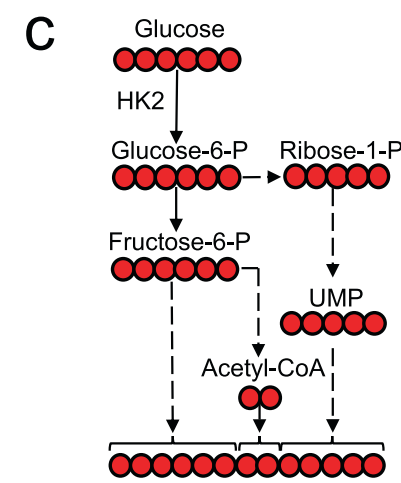

UDP-GICNAC

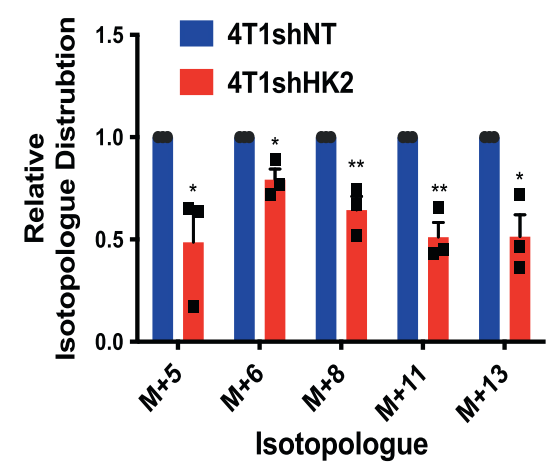

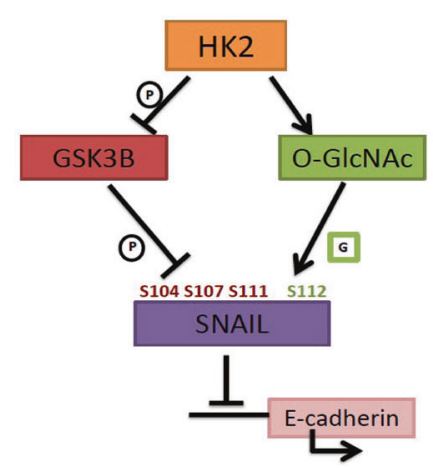

Fig. 10 HK2 deficiency inhibits the incorporation of metabolically labeled glucose into UDP-N-acetylglucosamine and reduces total and SNAIL O-GIcNAc modification. a Left: representative immunoblot images showing total O-GlcNAc protein modification in MMTV-PyMT mammary gland tumors after systemic deletion of HK2. Right: quantification of total O-GIcNAc modifications in control primary tumors ( $n=7$ tumors from three mice) and primary tumors after systemic HK2 deletion ( $n=9$ tumors from six mice). Results are the mean \pm SEM; ${ }^{*} p=0.016$ using unpaired two-tailed $t$-test. $\mathbf{b}$ Immunoblot images of total O-GIcNAc protein modification in 4T1 cells after HK2 silencing and 67NR cells after HK2 overexpression (representative of two immunoblots from two independent experiments). c Tracing of UDP-GIcNAc isotopomers after culturing $4 \mathrm{~T} 1$ and $4 \mathrm{~T} 1 \mathrm{shHK2}$ cells with $5 \mathrm{mM}$ of $\mathrm{U}^{13} \mathrm{C}_{6}{ }^{-}$ glucose for $5 \mathrm{~min}$. Tracing was performed by ion chromatography (IC-MS). Data shown as fold-changes relative to the control 4 T1shNT cells for each isotopomer for UDP-GICNAc with natural abundance correction and represented as the mean \pm SEM. ${ }^{\star} p<0.05,{ }^{\star \star} p<0.01(M+5 p=0.03, M+6$ $p=0.015, M+8 p=0.005, M+11 p=0.0023, M+13 p=0.01)$ from triplicate experiments using two-tailed $t$-test $(n=3)$. The schematic shows the contribution $U^{13} \mathrm{C}_{6}$-glucose-6-P to the UDP-GICNAc isotopomers. $\mathbf{d}$ Immunoprecipitation with anti-O-GIcNAc and immunoblotting with anti-SNAIL after transient transfection of $4 \mathrm{~T} 1$ and 4 T1shHK2 cells with GFP-SNAIL (representative of two independent experiments). e Schematic depicting how HK2 affects SNAIL protein stability and activity. Uncropped blots are provided as a Supplementary Fig. 16. Source data are provided as a Source Data file.

presently speculative, we also cannot exclude the possibility that HK1 may serve similar AKAP-like roles.

In summary, we have discovered a novel phenomenon, wherein glucose metabolites regulate the activity of GSK3 with far-reaching and profound biological significance. HK2 can sequester GSK3 and facilitate its phosphorylation. However, a metabolic slow-down that leads to the accumulation of the most upstream glucose metabolite, G6P, could trigger the dephosphorylation and consequent activation of GSK3. In turn, GSK3 could affect cell proliferation, cell growth, cell survival by multiple mechanisms, and tumorigenesis. We showed that HK2 could affect the levels of three proteins that are known targets of GSK3: MCL1, NRF2, and SNAIL. Here, we also showed that systemic deletion of HK2, which emulates drug therapy, inhibited breast cancer metastasis in a mouse model of breast cancer metastasis. Our results strongly suggest that the effect of HK2 on metastasis is mostly cell autonomous, although we cannot completely exclude non-cell autonomous effects. We have demonstrated that HK2 depletion reduced SNAIL protein levels in a GSK3-dependent manner and in turn affected the expression of EMT genes and metastasis. It was shown that the extent of GlcNAcylation is induced in human breast cancer and is further elevated in metastatic lymph nodes ${ }^{55}$. It was also reported that 
O-GlcNAcylation and GlcNAcylation in general are important for breast cancer tumor progression and metastasis ${ }^{49,55}$ and that SNAIL phosphorylation by GSK3 could be counteracted by O-GlcNAcylation ${ }^{50}$. Therefore, we examined the effect of HK2 depletion on the hexosamine pathway, as well as general and SNAIL-specific O-GlcNAcylation. Our findings showed that HK2 depletion markedly reduced the hexosamine pathway and both general and SNAIL-specific O-GlcNAcylation. Thus, our results showed that both the non-catalytic activity, uncovered here, and the catalytic HK2 activity contribute to the regulation of SNAIL protein levels and metastasis. Importantly, as we had previously suggested the feedback inhibition of HK2 by its own catalytic product G6P could be used as a strategy to target HK2 for cancer therapy by developing mimetics of G6P or 2DG6P to inhibit its activity ${ }^{51}$. Using this approach, inhibitors that selectively target HK2 and not HK1 were developed ${ }^{7}$. Since G6P or 2DG6P also dissociates GSK3 from HK2 thereby increasing the activity of GSK3, this approach could inhibit both the glycolytic activity of HK2 as well as its moonlighting activity as a promoter of metastasis.

\section{Methods}

Cell culture, transfection, and transduction. HCT116, HEK293, Huh7, Нep3B, A549, Hela, and 4T1 cell lines were obtained from the American Type Culture Collection and were grown according to recommendations. Ratla cells and MEFs generation were previously described ${ }^{56,57}$. MI5-4 CHO cells were originally provided by Dr. John Wilson and were previously described ${ }^{22}$. CHO cells were cultured in a-MEM supplemented with $10 \%$ FBS (Gemini) and $2 \mathrm{mM}$ glutamine. All other cells were cultured in DMEM (Invitrogen) containing 10\% FBS (Gemini). For glucose starvation, the medium was replaced with glucose-free DMEM (Invitrogen) containing $10 \%$ dialyzed FBS (Gemini) after washing with PBS. For immunoprecipitation, $2 \times 10^{6}$ HEK293-HK2-HA cells were plated in 6-cm dishes 1 day before transfection using $2 \mu \mathrm{g}$ of each plasmid. After $24 \mathrm{~h}$ of transfection, cells were used for experiments. For transient transfection of shRNA plasmids in HEK293-HK2HA cells, $2.5 \times 10^{5}$ cells were plated in 6-well plates one day before transfection using $3 \mu \mathrm{g}$ of each shRNA plasmid and Lipofectamine 2000 . After $48 \mathrm{~h}$ of transfection, cells were used for experiments. For the tet-inducible shRNA expression system, each shRNA sequence was inserted into the Tet-pLKO-puro vector (a gift from Dmitri Wiederschain; Addgene plasmid \#21915). The most efficient shRNA sequences we used were TRCN0000281204 for G6PDsh, TRCN0000274975 for GPGDsh, and TRCN0000290649 for GPIsh. For lentivirus production, each lentiviral vector was cotransfected with pMD2.G and psPAX2 (gifts from Didler Trono; Addgene plasmids \#12259 and \#12260, respectively) in 293 T cells using Lipofectamine 2000 as described in a protocol on the Addgene website. Lentivirus infection was performed overnight in the presence of polybrene, and selection was carried out with $10 \mu \mathrm{g} / \mathrm{ml}$ blasticidin.

The cDNA for rat HK2 was subcloned into the pcDNA3-HA vector. Sitedirected mutagenesis of HK2-DA (D209A/D657A; a non-glucose-binding mutant), SA (S155A/S603A; a catalytically inactive mutant), and dMT (deletion of 1-20aa) was performed using QuickChange II XL (Stratagene) according to the manufacturer's instructions. The HA-tagged cDNAs were subcloned into the pLenti6-D-TOPO vector (Invitrogen). The cDNA for human GSK3 $\beta$ was subcloned into the pCMV-myc vector. cDNA for human PRKARla was subcloned into the pLenti6-D-TOPO vector. All lentiviruses were produced using the BLOCK-iT lentiviral expression system (Invitrogen) according to the manufacturer's instructions.

Polyclonal 4T1 cells with stable HK2 knockdown were generated after infection with pLenti6-blast vector expressing a mouse HK2 hairpin and selection with blasticidin. The HK2 mouse target sequence was $5^{\prime}$-GCATATGATCGCCTGCTT AT-3'. Flag-Snail-6SA and GFP-SNAIL-6SA were obtained from Mien-Chie Hung through Addgene (Addgene plasmid \#16225; http://n2t.net/addgene:16225; RRID:Addgene_16225) and cloned into the PCW-puro vector (addgene: 50661, following the removal of Cas9 with NheI and BamHI) using Gibson Assembly. The ViraPower ${ }^{\mathrm{TM}}$ lentiviral expression system from Thermo Fischer Scientific was used for virus production. The pLenti6-blast and pBABE-blast vector were both used to overexpress rat wild-type HK2 and kinase dead HK2 (S155A/S603A). Cells were selected with $2 \mu \mathrm{g} / \mathrm{ml}$ puromycin or $8 \mu \mathrm{g} / \mathrm{ml}$ blasticidin for 5 days. The established murine mammary 4T1, 67NR, and the isolated PyMT cells were cultured in highglucose DMEM media with $10 \%$ serum and $1 \%$ pen/strep in a $37^{\circ} \mathrm{C}$ incubator. The $4 \mathrm{~T} 1$ cells were sent for screening with the IDEAX Impact I panel before orthotopic transplantation into mice. The cells used to test for total O-GlcNAc levels, and for immunoprecipitation experiments were plated in $5 \mathrm{mM}$ glucose DMEM with $10 \%$ serum for at least 5 days prior to harvesting for experiments.

Immunoprecipitation and immunoblotting. For immunoprecipitation, cells grown in 6-cm dishes were lysed in IP buffer ( $50 \mathrm{mM}$ Tris- $\mathrm{Cl}$ ( $\mathrm{pH} 8.0$ ), 0.5\% NP-
40, $150 \mathrm{mM} \mathrm{NaCl}, 1 \mathrm{mM}$ EGTA, $1 \mathrm{mM}$ EDTA) containing phosphatase inhibitors (10 mM sodium pyrophosphate, $20 \mathrm{mM} \beta$-glycerophosphate, $100 \mathrm{mM} \mathrm{NaF}$ ) and protease inhibitor cocktail (Roche Applied Science). Protein extracts were incubated with each antibody with rotation for $2 \mathrm{~h}$ and then added to protein A/G agarose beads (Santa Cruz, sc-2003) for an additional $1 \mathrm{~h}$. The immunoprecipitates were washed three times with IP buffer and then resuspended in sample buffer for immunoblotting.

For immunoblotting, protein extracts were prepared in lysis buffer as described before ${ }^{58}$. Briefly, cells were lysed in lysis buffer (20 mM HEPES, $1 \%$ TX-100, $150 \mathrm{mM} \mathrm{NaCl}, 1 \mathrm{mM}$ EGTA, $1 \mathrm{mM}$ EDTA) containing phosphatase inhibitors ( $10 \mathrm{mM}$ sodium pyrophosphate, $20 \mathrm{mM} \beta$-glycerophosphate, $100 \mathrm{mM} \mathrm{NaF}, 5 \mathrm{mM}$ IAA, $20 \mathrm{nM}$ okadaic acid (OA)) and protease inhibitor cocktail. Solubilized proteins were collected by centrifugation and quantified using protein assay reagent (Bio-Rad). Samples containing equal amounts of protein were resolved by electrophoresis on an $8-10 \%$ gel and transferred to polyvinylidene difluoride membranes (Bio-Rad). Standard enhanced chemiluminescence (ECL) was used for film exposure, and an Azure or LI-COR machine was used to image the blot. ImageJ or LI-COR imaging software was used to quantify bands on the blots. To determine total O-GlcNAc levels, cells were lysed in RIPA buffer with a Pierce ${ }^{\mathrm{TM}}$ protease inhibitor mini tablet and a Pierce ${ }^{\mathrm{TM}}$ phosphatase inhibitor mini tablet (1 tablet per $10 \mathrm{ml}$ of lysis buffer). The lysates were incubated on ice for $30 \mathrm{~min}$ and centrifuged at $13,950 \times g$ for $10 \mathrm{~min}$ before immunoblotting.

Immunofluorescence. Cells were plated in triplicate in 4-well culture slides. Wildtype or 6SA GFP-tagged SNAIL plasmid $(0.75 \mu \mathrm{g})$ was transiently transfected by using Lipofectamine 2000 overnight. Cells were fixed in $4 \%$ paraformaldehyde (PFA) for $30 \mathrm{~min}$ followed by four washes in ice cold PBS. After fixation of the cells, the localization of SNAIL proteins (green) and nuclei (blue; Hoechst 33342) were examined under a confocal microscope (Zeiss Lsm 700), in at least 40 randomly selected fields at $\times 400$ magnification.

Hexokinase activity assay. Hexokinase activity in whole-cell lysates and mitochondrial fractions was measured using a standard glucose-6-phosphate (G6P) dehydrogenase (G6PDH)-coupled spectrophotometric assay as described previously ${ }^{56}$. Whole-cell lysates were prepared by brief sonication in homogenization buffer containing $45 \mathrm{mM}$ Tris- $\mathrm{HCl}, 50 \mathrm{mM} \mathrm{KH} 2 \mathrm{PO} 4,10 \mathrm{mM}$ glucose, and $0.5 \mathrm{mM}$ EGTA. Hexokinase activity was measured as the total glucosephosphorylating capacity of whole-cell lysates in a final assay mixture containing $50 \mathrm{mM}$ triethanolamine chloride, $7.5 \mathrm{mM} \mathrm{MgCl} 2,0.5 \mathrm{mM}$ EGTA, $11 \mathrm{mM}$ monothioglycerol, $4 \mathrm{mM}$ glucose, $6.6 \mathrm{mM}$ ATP, $0.5 \mathrm{mg} / \mathrm{ml} \mathrm{NADP}$, and $0.5 \mathrm{U} / \mathrm{ml} \mathrm{G6PDH}$, $\mathrm{pH}$ 8.5. Hexokinase activity in each sample was calculated as the coupled rate of NADPH formation by the Lambert-Beer law as follows: $[(\mathrm{A} 340 / t)] \times$ dilution factor/[protein], where $\left(6.22 \mathrm{mM}^{-1} \mathrm{~cm}^{-1}\right)$ is the extinction coefficient for NADPH at $340 \mathrm{~nm}(t=$ time, [protein] $=$ protein concentration $)$.

Quantitation of G6P in cells by fluorometric assay. An enzymatic fluorometric assay to quantify G6P was performed following the method described previously ${ }^{59}$ with minor modifications. Briefly, samples were extracted from $5 \times 10^{6}$ cells with $\mathrm{MeOH} /$ $\mathrm{CHCl}_{3}$ and stored at $-80^{\circ} \mathrm{C}$. Just prior to the assay, the extracted samples were dissolved in $50 \mu \mathrm{l}$ of Millipore water, and then $10 \mu \mathrm{l}$ of each extraction sample were incubated for $30 \mathrm{~min}$ at room temperature in a 96-well plate with $90 \mu \mathrm{l}$ of an assay cocktail containing $50 \mathrm{mM}$ triethanolamine (TEA, pH 7.6), $1.0 \mathrm{mM} \mathrm{MgCl} 2,100 \mu \mathrm{M}$ $\mathrm{NADP}+, 10 \mu \mathrm{M}$ resazurin, $1.5 \mathrm{U} / \mathrm{ml} \mathrm{G} 6 \mathrm{PD}$, and $0.2 \mathrm{U} / \mathrm{ml}$ diaphorase). In this assay, G6P is oxidized by G6P dehydrogenase in the presence of NADP+, and stoichiometrically generated NADPH is then amplified by the diaphorase-resazurin system. Fluorescence at $590 \mathrm{~nm}$ was measured using excitation at $530 \mathrm{~nm}$. Background fluorescence was corrected by subtracting the value of the blank for each sample, and G6P concentrations were calculated from a standard curve. Fluorescence was measured using a Tecan Infinite M200 PRO plate reader in 96-well black assay plates.

Protein stability assays. For measuring MCL1 protein stability in MI5-4 CHO cells and in MI5-4 CHO cells expressing HK2 or for measuring endogenous SNAIL protein stability in $4 \mathrm{~T} 1$ and $4 \mathrm{~T} 1 \mathrm{shHK} 2$ cells, cells were plated on 6-well plates at a seeding density of $2 \times 10^{5}$ cells/well. Cells were treated with cycloheximide $(100 \mu \mathrm{M})$ for the indicated time points. For wild-type GFP-tagged or 6SA GFPtagged SNAIL, $1.5 \mu \mathrm{g}$ of plasmid was transiently transfected by using Lipofectamine 2000 overnight.

Enzyme-linked immunosorbent assay for monitoring the HK2/PRKAR1a and HK2 GSK3 $\beta$ interaction. Enzyme-linked immunosorbent assays were conducted in Pierce Nickel (His) or Glutathione (GST) 96-well coated plates. The plates were respectively coated with His-PRKARla $(50 \mathrm{nM}$; Sino Biological) or GST-GSK3 $\beta$ ( $50 \mathrm{nM}$; Abcam), in coating buffer (phosphate-buffered saline containing $0.5 \mathrm{mM}$ phenylmethanesulfonyl fluoride and $1 \mathrm{mM}$ dithiothreitol) and incubated overnight at $4{ }^{\circ} \mathrm{C}$. Thereafter, unbound protein was removed by washing the wells three times with $100 \mu \mathrm{l}$ of washing buffer (phosphate-buffered saline containing $0.05 \%$ Tween 20 ) and blocking buffer (coating buffer containing $0.6 \%$ skimmed milk powder and $0.05 \%$ Tween 20 ) was added ( $100 \mu \mathrm{l}, 1 \mathrm{~h}$, room temperature). After removal, monitoring of interactions of PRKAR1a or GSK3 $\beta$ with HK2 was carried out in 
coating buffer and increasing concentration of Myc-HK2 protein (OriGene; 0-64 nM, $40 \mu \mathrm{l} /$ well, $2 \mathrm{~h}$, room temperature). For G6P-induced binding inhibition, $30 \mathrm{~min}$ before the end of the incubation, G6P $(0-100 \mu \mathrm{M})$ is added directly to the wells. Unbound protein was removed by washing the wells three times with $100 \mu \mathrm{l}$ of washing buffer and bound Myc-HK2 was detected with monoclonal anti-Myc HRP-conjugated antibody (Abcam; 1:5000 in blocking buffer, $1 \mathrm{~h}$, room temperature). Bound PRKAR1a or GSK3 $\beta$ were detected by incubation with rabbit anti- PRKAR1a antibody (Cell Signaling; 1:2000 in blocking buffer) or mouse antiGSK3 $\beta$ antibody (Millipore; 1:2000 in blocking buffer) and HRP-conjugated antirabbit or mouse IgG (1:3000, $1 \mathrm{~h}$, room temperature). For each assay, non-specific binding is also conducted as described in figures.

Each antibody incubation step was followed by washing. The HRP reaction was initiated by addition of 3,3',5,5'-tetramethylbenzidine enzyme-linked

immunosorbent assay substrate solution (Sigma) and terminated after $30 \mathrm{~min}$ by adding $\mathrm{H} 2 \mathrm{SO} 4(2 \mathrm{M} ; 50 \mu \mathrm{l} /$ well). The colored reaction product was quantified by measuring A450 $\mathrm{nm}$ in a Cytation 1 plate reader (Biotek).

Enzyme-linked immunosorbent assay for monitoring the PRKAR1a/HK2/GSK3 $\beta$ interaction. Binding assay is conducted on Pierce Nickel-coated 96-well plates and after successive incubation with His-PRKAR1a and Myc-HK2 as described above, unbound proteins will be washed and blocking buffer will be added for $1 \mathrm{~h}$ at room temperature. Thereafter, GST-GSK3 $\beta$ is added at increasing concentration (0-64 nM; $40 \mu \mathrm{l} /$ well, $2 \mathrm{~h}$, room temperature). For G6P-induced binding inhibition, $30 \mathrm{~min}$ before the end of the incubation, G6P $(0-1000 \mu \mathrm{M})$ is added directly to the wells. Unbound protein was removed by washing the wells as described above and bound GST-GSK3 $\beta$ was detected with monoclonal anti-GST HRP-conjugated antibody (Abcam; 1:5000 in blocking buffer, $1 \mathrm{~h}$, room temperature). Bound PRKAR1a or HK2 were detected by incubation with rabbit anti- PRKAR1a antibody (Cell Signaling; 1:2000 in blocking buffer) or rabbit anti-HK2 antibody (Cell Signaling; 1:2000 in blocking buffer) and HRP-conjugated anti-rabbit IgG (1:3000, $1 \mathrm{~h}$, room temperature). For each assay, non-specific binding is also conducted as described in figures and HRP reaction is conducted as described above.

Monitoring of GSK3 phosphorylation in the HK2/PRKAR1 $\alpha / G S K 3 \beta$ complex. Enzyme-linked immunosorbent assays were conducted in Pierce Nickel-8-wellstrip-coated plates. The plates were coated with His-HK2 (50 nM; Creative Biomart) in coating buffer and incubated overnight at $4{ }^{\circ} \mathrm{C}$. Unbound proteins is then washed and blocking buffer is added for $1 \mathrm{~h}$ at room temperature. Thereafter, MycPRKAR1 $\alpha$ (32 nM; Creative Biomart), PKAc (20 nM; Promega) and GST-GSK3 $\beta$ (32 nM; Abcam) successively, each for $1 \mathrm{~h}$ incubation at room temperature, and unbound protein will be carefully washed after each incubation. After all proteins are bound, kinase buffer ( $1 \mathrm{mM}$ ATP and $10 \mathrm{mM} \mathrm{MgCl}_{2}$ in Tris $\left.20 \mathrm{mM}, \mathrm{pH} 7.4\right)$ with or without cyclic AMP $(10 \mu \mathrm{M})$ is added to all appropriate wells ( $1 \mathrm{~h}$; room temperature). After incubation, kinase buffer is washed and appropriate antibody will be added to the wells de detect bound proteins (P-GSK3 $\beta$, total GSK3, PRKAR1 $\alpha, \mathrm{HK} 2$, and PKAc) and incubated overnight at $4{ }^{\circ} \mathrm{C}$. After washing, total bound GST-GSK3 $\beta$ was detected with monoclonal anti-GST HRP-conjugated antibody, and bound P-GSK3 $\beta$, PRKAR1 $\alpha, \mathrm{HK} 2$ and PKAc antibodies are detected with HRP-conjugated anti-rabbit IgG (1:3000, $2 \mathrm{~h}$, room temperature). The HRP reaction is conducted as described above.

For G6P-induced binding inhibition, G6P $(1 \mathrm{mM})$ is added $30 \mathrm{~min}$ before the end of the incubation with GST-GSK3 $\beta$, before the addition of kinase buffer.

Negative control reactions are conducted as described above, in absence of HisHK2 or Myc-PKAR1a.

Enzyme-linked immunosorbent assay for monitoring the PRKAR1a/HK2 interaction in presence of FMP-API-1. Binding assay is conducted on Pierce Nickel-coated 8well strip plates and after successive incubation with His-PRKAR1 $\alpha$ and Myc-HK2 as described above, unbound proteins will be washed and blocking buffer will be added for $1 \mathrm{~h}$ at room temperature. Thereafter, FMP-API- 1 is added directly to the wells $30 \mathrm{~min}$ before the end of the incubation with Myc-HK2 at increasing concentration $(0-1000 \mu \mathrm{M})$. Unbound protein was removed by washing the wells as described above and bound Myc-HK2 was detected with monoclonal anti-Myc HRP-conjugated antibody (Abcam; 1:5000 in blocking buffer, $1 \mathrm{~h}$, room temperature). HRP reaction is then conducted as described above.

Metabolic labeling. For metabolic tracing in A549 cells, $7.0 \times 10^{5}$ cells were plated onto 6-well plates for next day pulse-labeling with $25 \mathrm{mM}\left[1,2^{-13} \mathrm{C}\right]$ glucose (Cambridge Isotope Laboratories). Isotope labeling experiments were performed for $4 \mathrm{~h}$, and extra plates were included for cell counts. At the time of collection, plates were washed twice with $1 \mathrm{ml}$ of $(9 \mathrm{~g} / \mathrm{l}) \mathrm{NaCl}$. Then, cells were incubated with $600 \mu \mathrm{l}$ mixed solvent (water:methanol:acetonitrile $=1: 1: 1$ ) containing $2 \mu \mathrm{lof} 2 \mathrm{mg} /$ $\mathrm{ml}$ Norvaline (SigmaAldrich) dissolved in distilled water as an internal standard, and then scraped down with cell scrapers. The solution was shaken at $1200 \mathrm{rpm}$ for $30 \mathrm{~min}$ and centrifuged at $16,000 \times g$ for $15 \mathrm{~min}$ at $4^{\circ} \mathrm{C}$. The supernatant $(280 \mu \mathrm{l})$ was transferred to a clean tube and lyophilized under nitrogen gas. The lyophilized samples were derivatized with $15 \mu \mathrm{l}$ of $2 \mathrm{wt} \%$ methoxylamine hydrochloride (Thermo Fisher) for $60 \mathrm{~min}$ at $42{ }^{\circ} \mathrm{C}$. Next, $35 \mu \mathrm{l}$ of N-methyl-N-(tert-butyldimethylsilyl)-trifluoroacetamide (MTBSTFA) $+1 \%$ tert-butyldimetheylchlorosilane (t-BDMCS) (SigmaAldrich) was added and the samples were incubated for $60 \mathrm{~min}$ at $75^{\circ} \mathrm{C}$. The derivatized samples were then centrifuged at $16,000 \times g$ for $5 \mathrm{~min}$ at $4{ }^{\circ} \mathrm{C}$, and the supernatant $(1 \mu \mathrm{l})$ was subjected to GC-MS measurement.

GC-MS analysis was performed using an Agilent 7890B GC equipped with a DB-5ms column $(30 \mathrm{~m} \times 0.25-\mathrm{mm}$ inner diameter; film thickness, $0.25 \mu \mathrm{m}$; Agilent $\mathrm{J} \& \mathrm{~W}$ Scientific). The front inlet temperature was $280^{\circ} \mathrm{C}$ and helium flow was maintained at $1.428 \mathrm{ml} / \mathrm{min}$. For intracellular lactate analysis, the column temperature was held at $60^{\circ} \mathrm{C}$ for $1 \mathrm{~min}$ followed by 1 -min of run time, rising at $10^{\circ} \mathrm{C} / \mathrm{min}$ to $320^{\circ} \mathrm{C}$ and holding for $1 \mathrm{~min}$ followed by a post run of $320^{\circ} \mathrm{C}$ for $9 \mathrm{~min}$. For the analysis of G6P and 6PG, the initial rate was held at $60^{\circ} \mathrm{C}$ for $1 \mathrm{~min}$ followed by 1 -min of run time, rising at $10^{\circ} \mathrm{C} / \mathrm{min}$ to $325^{\circ} \mathrm{C}$ and holding for $10 \mathrm{~min}$ followed by a post run of $60^{\circ} \mathrm{C}$ for $1 \mathrm{~min}^{60,61}$. The peak area of each quantified ion was calculated and corrected for natural isotope abundances by following the procedure by Fernandez et al. ${ }^{62}$, and then normalized by the peak area of norvaline as an internal standard and cell number.

For metabolic tracing, in 4T1 and 4T1shHK2 cells, the cells were plated on $6 \mathrm{~cm}$ plate in triplicate $\left(3 \times 10^{5}\right)$ in $5 \mathrm{mM}$ glucose DMEM media for $48 \mathrm{~h}$. Cells were washed in PBS and $5 \mathrm{mM}$ of uniformly labeled C-13 glucose in DMEM with $10 \%$ dialyzed FBS was added for 5 min following extraction in $1 \mathrm{ml}$ of cold 90/10 acetonitrile/water. Cells were collected using a cell scrapper, vortexed for $2 \mathrm{~min}$, and centrifuged at highest speed for $5 \mathrm{~min}$. The supernatant was transferred to clean Eppendorf tube and sent to MD Anderson Cancer Center's Proteomics and Metabolomics Core Facility for analysis by Ion chromatography mass spectrometry (IC-MS). One $6 \mathrm{~cm}$ plate was collected for western blot. Cell number was counted on extra 6-well plate and protein concentration were quantified with remaining cell pellet.

Extracellular lactate measurements. Extracellular lactate concentrations were measured using a YSI 2700 Bioanalyzer (YSI).

Mouse strains and treatment protocol. C57BL/6 MMTV-PyMT and HK2f/f;UBC $C r e^{E R T 2}$ mice were previously described ${ }^{51}$. MMTV-PyMT;HK2f/f mice were crossed with $H K 2^{f / f} ; U B C-C r e^{E R T 2}$ or $H K 2^{f / f}$ mice to generate experimental and control mice on a C57BL/ 6 background. Once a primary tumor was palpable ( 12 weeks old), $0.1 \mathrm{ml}$ of $30 \mathrm{mg} / \mathrm{ml}$ tamoxifen was injected IP for 7 consecutive days to systemically delete HK2 as previously described ${ }^{51}$. At the tumor endpoint $(20 \%$ weight loss from baseline, $15 \%$ weight gain compared to aged-matched controls, tumor size greater than $15 \%$ of the body weight, tumor mass $>2 \mathrm{~cm}$, tumor ulceration, pallor, respiratory distress, or inability to ambulate), the mice were euthanized, and their lungs were analyzed for metastases.

$M M T V$-rtTA, Tet(O)Cre, and LSL-luc mice were purchased from Jackson Laboratory.

MMTV-PyMT;Hk2fff;LSL.Luc;MMTV.rtTATet(O)Cre mice were generated by first crossing MMTV-rtTA mice with LSL.Luc and Tet(O)Cre mice to generate LSL.Luc;MMTV.rtTATet(O)Cre mice. These mice were crossed with MMTVPyMT;Hk2f/f mice.

$\mathrm{Balb} / \mathrm{cJ}$ mice were purchased from Jackson Laboratory and NOD.Cg-Prkdcscid (NOD-F) mice from TACONIC

All animal work was conducted according to the ethical regulations set forth by the federal government, as reviewed and approved through the Office of Animal Care and Institutional Biosafety (OACIB) within the Office of the Vice Chancellor for Research at the University of Illinois, Chicago.

Histochemistry. Mammary tumor tissues and PBS-inflated lung lobes were collected, and macroscopic lung lesions were counted visually. The tissues were fixed in $10 \%$ formalin for $48 \mathrm{~h}$. Tissues were paraffin embedded and sectioned for hematoxylin and eosin (H\&E) staining (5- $\mathrm{mm}$ sections). Microscopic lung lesions were counted using a microscope.

Primary tumor isolation and processing. Tumors isolated from MMTV-PyMT mice were isolated for scRNA-seq, western blotting, and orthotopic transplantation. The mice were sacrificed close to the tumor endpoint (primary tumor $>2 \mathrm{~cm}$ ) Primary tumors were dissected and washed several times in PBS with $1 \times$ pen/strep The tumors were chopped into 1-mm pieces with a sterile scalpel and placed in collagenase for $1 \mathrm{~h}$ at $37^{\circ} \mathrm{C}$ on a shaker. The collagenase mixture consisted of $10 \%$ type IV collagenase and $1 \%$ DNase dissolved and sterile filtered in DMEM. After digestion, the cells were spun for $5 \mathrm{~min}$ at $1000 \mathrm{rpm}$. The supernatant was aspirated, and $2 \mathrm{ml}$ of ACK lysis buffer was used to resuspend the pellet for $2 \mathrm{~min}$. The mixture was centrifuged again, and the pellet was washed in DMEM or PBS at least twice before proceeding with the experiment. For scRNA-seq, the pellet was resuspended in PBS and filtered through a $40-\mu \mathrm{m}$ filter to isolate single cells for sequencing. The cells were counted with trypan blue staining to determine cell viability before proceeding with the Drop-seq protocol as previously described ${ }^{42,43}$.

Single-cell RNA-seq and bioinformatics. For scRNA-seq, the PyMT tumors were isolated as described in the section regarding primary tumor isolation and processing. In total, we sacrificed 15 mice ( 7 and 8 replicates of primary tumors from the PyMT mouse model with or without systemic HK2 deletion, respectively) and performed the DropSeq protocol in each of the samples. The sequencing was also done independently. The pooling was done only after mapping, when we pooled 
the 15 matrices together to perform Seurat analysis. The pellet was resuspended in PBS and filtered through a $40-\mu \mathrm{m}$ filter to isolate single cells for sequencing. The cells were counted with trypan blue staining to determine cell viability before proceeding with the Drop-seq protocol ${ }^{41}$. To isolate single-cell droplets, $1.65 \times 10^{5}$ cells were resuspended in $1.5 \mathrm{ml}$ of $0.1 \%$ BSA PBS and loaded on a microfluidic chip. Cells were lysed in the droplet, and mRNA was bound to a unique molecular identifier (UMI) on barcoded beads. The individual droplets were broken down and pooled in a reverse transcriptase mixture. Single-cell transcriptomes attached to microparticles (STAMPs) were created by reverse transcription. The STAMPS were PCR amplified, and unhybridized DNA was removed with exonuclease I treatment. The UIC Research Resources Center (RRC) used TapeStation and Qubit to check the cDNA quality and quantity of the amplified products. The Nextera XT kit was used to make the libraries, which were then sequenced by an Illumina NextSeq 500. The raw sequence data were filtered and aligned to the mouse genome (mm10) with the addition of the PyMT gene sequence to help identify positive tumor cells. The digital expression matrix file containing UMIs were analyzed with the Seurat package version 2.3.463 $\mathrm{R}$ version 3.5.3. Mitochondrial genes were removed from the matrices before being analyzed in Seurat. Only genes present in at least 3 cells were kept. In order to filter out low-quality cells and likely doublets, we excluded cells with less than 200 and more than 6000 genes. Normalization and finding variable genes were done using default parameters using the functions "NormalizeData" and "FindVariableGenes", respectively. Data was scaled using the function "ScaleData" regressing only the variable "nUMI". No batch correction was performed. "RunPCA" was ran on the variable genes. Clusters were identified using the function "FindClusters" using a resolution of 0.6 and 9 dimensions that were selected using a $p$-value $<10^{-10}$ calculated using "JackStraw" function as cutoff. Dimensionality reduction was done using the function "RunTSNE" using 9 dimensions as described earlier. We checked for over-clustering considering clusters for identical top genes. Top markers for each clusters were identified using the function "FindAllMarkers" using default parameters except for "only.pos= TRUE". Based on the expression of top markers we annotated the cell type of each cluster using cell type markers used previously in scRNAseq data ${ }^{64,65}$. We confirm the high expression of epithelial and mesenchymal markers in clusters 14 and 15 scoring all the cells with expression of the programs "GO_EPITHELIUM_DEVELOPMENT" and "HALLMARK_EPITHELIAL_MESENCHYMAL TRANSITION" from MSigDB collections (v6.2 updated in July 2018)66 using the Seurat function "AddModuleScore".

Quantitative RT-PCR. Total RNA was extracted with TRIzol reagent (Invitrogen) or a Qiagen RNeasy mini kit. Quantitative PCR was performed with a BIO-RAD iTaq Universal SYBR Green One-Step Kit and system. Each sample was prepared in triplicate and normalized to B-actin mRNA levels.

Orthotopic transplantation. Cells from MMTV-PyMT;HK2/ff mice were isolated as described above. The pellet was resuspended in PBS and filtered through a 75$\mu \mathrm{m}$ filter before the cells were plated in $10 \% \mathrm{FBS}, 1 \%$ pen/strep, and high-glucose DMEM. The cells were then infected with either adenovirus expressing GFP or adenovirus expressing GFP-Cre at a MOI of 1000 to delete HK2. Deletion of HK2 was verified via western blotting. The cells were orthotopically transplanted into the mammary fat pads of 6-week-old NOG-F female mice. Briefly, the cells were trypsinized, resuspended, and counted with trypan blue staining to determine cell viability and number. Cells $\left(1 \times 10^{5}\right)$ were resuspended in $100 \mu \mathrm{l}$ of a 1:1 mixture of PBS and Matrigel (Corning). They were then transplanted into the fourth mammary fat pads of NOG-F mice. Similarly, approximately $5 \times 10^{5} 4 \mathrm{~T} 1$ and 4T1shHK2 cells resuspended in $100 \mu \mathrm{l}$ of a 1:1 mixture of PBS and Matrigel (Corning) were transplanted into the fourth mammary fat pads of 6 weeks old syngeneic $\mathrm{Balb} / \mathrm{cJ}$ female mice. The recipient mice were monitored until they reached the tumor endpoint. The lungs were then isolated and processed for H\&E staining to quantify lung metastasis. Finally, $5 \times 10^{4}$ cells of 4 T1shHK2 with dox inducible Empty Vector or 6SA-SNAIL cells were resuspended in $100 \mu \mathrm{l}$ of 1:1 in PBS and Matrigel (Corning) mixture and transplanted into the fourth mammary fat pad of syngeneic Balb/cJ mice. The following day DOX $(1 \mathrm{ml} / \mathrm{ml}$ in water with $5 \%$ sucrose) was added to both groups of mice for 1 week. The recipient mice were monitored until they reached tumor endpoint and lungs were isolated and processed for H\&E stain to quantify lung metastasis.

Transwell migration and invasion assays. For the transwell migration assay, $1 \times 10^{5}$ cells in $200 \mu \mathrm{l}$ were incubated in 24-plate chamber wells containing 8.0- $\mathrm{m}$ filter in high-glucose DMEM with $0 \%$ serum. The lower chamber contained $750 \mu$ lo highglucose DMEM with $20 \%$ serum as a stimulant. After $12 \mathrm{~h}$, the cells were washed twice in PBS, and the nonmigrated cells were scraped away with a cotton swab. The cells were fixed in methanol and stained with crystal violet. Migrated cells in five random fields were counted with Image J (version 1.51). For the transwell invasion assay, $1 \times 10^{5}$ cells in $500 \mu \mathrm{l}$ were incubated in gel-coated 24-plate chamber wells containing an $8.0-\mu \mathrm{m}$ filter in DMEM containing $5 \mathrm{mM}$ glucose and $0 \%$ serum. The lower chamber contained $750 \mu \mathrm{l}$ of DMEM containing $5 \mathrm{mM}$ glucose and $20 \%$ serum as a stimulant. After $24 \mathrm{~h}$, the cells were washed twice in PBS, and the nonmigrated cells were scraped away with a cotton swab. The cells were fixed with methanol and stained with crystal violet. Migrated and invaded cells in ten random fields were counted with Image J.
Antibodies: Supplementary Table 1

Recombinant Proteins: Supplementary Table 1

Chemicals and Enzymes: Supplementary Table 1

Commercial Assay Kits: Supplementary Table 1

Primers: Supplementary Table 2

Statistical analysis. Unless otherwise indicated, statistically significant differences were assessed by unpaired Student's $t$-test when two groups were compared or oneway ANOVA test when more than two groups were compared. Data were expressed as the mean \pm SEM as indicated in the figure legends. Unless otherwise indicated, the criterion for statistical significance was set at ${ }^{*} p<0.05,{ }^{* *} p<0.01$, *** $p<0.001, * * * * p<0.0001$. Statistical analyses were performed using GraphPad Prism Software Version 8.0 and Microsoft Excel. There is one example in the paper in which one mouse was excluded based on analysis by Prism (Fig. 9e). This figure shows that transient inducible expression of SNAIL rescues the ability of $4 \mathrm{~T} 1$ shHK2 cells to metastasize. All five mice showed the same trend. However, one mouse had more than 10-fold higher basal metastases when compared to the rest of the mice. The GraphPad Prism Software Version 8.0 recognized this mouse as an outlier and therefore this mouse was excluded from the analysis.

Reporting summary. Further information on research design is available in the Nature Research Reporting Summary linked to this article.

\section{Data availability}

All data are included in the paper and supplementary information files. Uncropped images for immunoblots are provided. Single-Cell RNA sequencing raw data were deposited to the database Gene Expression Omnibus (GEO) [https://www.ncbi.nlm.nih.gov/geo) under the accession number GSE148445]. Raw data of metabolic tracing experiments are available upon request.

Received: 9 July 2021; Accepted: 20 January 2022;

Published online: 16 February 2022

\section{References}

1. Hay, N. Reprogramming glucose metabolism in cancer: can it be exploited for cancer therapy? Nat. Rev. Cancer 16, 635-649 (2016).

2. Robey, R. B. \& Hay, N. Mitochondrial hexokinases, novel mediators of the antiapoptotic effects of growth factors and Akt. Oncogene 25, 4683-4696 (2006).

3. Patra, K. C. et al. Hexokinase 2 is required for tumor initiation and maintenance and its systemic deletion is therapeutic in mouse models of cancer. Cancer Cell 24, 213-228 (2013).

4. DeWaal, D. et al. Hexokinase-2 depletion inhibits glycolysis and induces oxidative phosphorylation in hepatocellular carcinoma and sensitizes to metformin. Nat. Commun. 9, 446 (2018).

5. Gregoriou, M., Trayer, I. P. \& Cornish-Bowden, A. Allosteric character of the inhibition of rat-muscle hexokinase B by glucose 6-phosphate. Eur. J. Biochem. 161, 171-176 (1986).

6. Gregoriou, M., Trayer, I. P. \& Cornish-Bowden, A. Isotope-exchange evidence that glucose 6-phosphate inhibits rat-muscle hexokinase II at an allosteric site. Eur. J. Biochem. 134, 283-288 (1983).

7. Lin, H. et al. Discovery of a novel 2,6-disubstituted glucosamine series of potent and selective hexokinase 2 inhibitors. ACS Med. Chem. Lett. 7, 217-222 (2016).

8. Magnani, M., Stocchi, V., Serafini, G. \& Chiarantini, L. The interaction of phosphorylated sugars with human hexokinase I. Biochim. Biophys. Acta 954 336-342 (1988).

9. Sui, D. \& Wilson, J. E. Structural determinants for the intracellular localization of the isozymes of mammalian hexokinase: intracellular localization of fusion constructs incorporating structural elements from the hexokinase isozymes and the green fluorescent protein. Arch. Biochem. Biophys. 345, 111-125 (1997).

10. Cross, D. A., Alessi, D. R., Cohen, P., Andjelkovich, M. \& Hemmings, B. A. Inhibition of glycogen synthase kinase- 3 by insulin mediated by protein kinase B. Nature 378, 785-789 (1995).

11. Doble, B. W. \& Woodgett, J. R. GSK-3: tricks of the trade for a multi-tasking kinase. J. Cell Sci. 116, 1175-1186 (2003).

12. Fang, X. et al. Phosphorylation and inactivation of glycogen synthase kinase 3 by protein kinase A. Proc. Natl Acad. Sci. USA 97, 11960-11965 (2000). 220413597 [pii].

13. Stambolic, V. \& Woodgett, J. R. Mitogen inactivation of glycogen synthase kinase- 3 beta in intact cells via serine 9 phosphorylation. Biochem. J. 303, 701-704 (1994).

14. Sutherland, C., Leighton, I. \& Cohen, P. Inactivation of glycogen synthase kinase-3 beta by phosphorylation: new kinase connections in insulin and growth-factor signalling. Biochem. J. 296, 15-19 (1993). 
15. Bennecib, M., Gong, C. X., Grundke-Iqbal, I. \& Iqbal, K. Role of protein phosphatase-2A and -1 in the regulation of GSK-3, cdk5 and cdc2 and the phosphorylation of tau in rat forebrain. FEBS Lett. 485, 87-93 (2000). [pii].

16. Robertson, H., Hayes, J. D. \& Sutherland, C. A partnership with the proteasome; the destructive nature of GSK3. Biochem. Pharm. 147, 77-92 (2018).

17. Maurer, U., Charvet, C., Wagman, A. S., Dejardin, E. \& Green, D. R. Glycogen synthase kinase-3 regulates mitochondrial outer membrane permeabilization and apoptosis by destabilization of MCL-1. Mol. Cell 21, 749-760 (2006).

18. Hayes, J. D., Chowdhry, S., Dinkova-Kostova, A. T. \& Sutherland, C. Dual regulation of transcription factor Nrf2 by Keap1 and by the combined actions of beta-TrCP and GSK-3. Biochem. Soc. Trans. 43, 611-620 (2015).

19. Rada, P. et al. Structural and functional characterization of Nrf2 degradation by the glycogen synthase kinase 3/beta-TrCP axis. Mol. Cell Biol. 32, 3486-3499 (2012).

20. Zhou, B. P. et al. Dual regulation of Snail by GSK-3beta-mediated phosphorylation in control of epithelial-mesenchymal transition. Nat. Cell Biol. 6, 931-940 (2004). ncb1173 [pii].

21. Cormier, K. W. \& Woodgett, J. R. Recent advances in understanding the cellular roles of GSK-3. F1000Res 6, https://doi.org/10.12688/ f1000research.10557.1 (2017)

22. O’Rear, J. L., Scocca, J. R., Walker, B. K., Kaiden, A. \& Krag, S. S. Chinese hamster ovary cells with reduced hexokinase activity maintain normal GDPmannose levels. J. Cell Biochem. 72, 56-66 (1999).

23. Ardehali, H. et al. Functional organization of mammalian hexokinase II. Retention of catalytic and regulatory functions in both the NH2- and $\mathrm{COOH}$ terminal halves. J. Biol. Chem. 271, 1849-1852 (1996).

24. Taylor, S. S. et al. Dynamics of signaling by PKA. Biochim. Biophys. Acta 1754, 25-37 (2005).

25. Kim, C., Xuong, N. H. \& Taylor, S. S. Crystal structure of a complex between the catalytic and regulatory (RIalpha) subunits of PKA. Science 307, 690-696 (2005).

26. Kwiatkowski, A. V., Gertler, F. B. \& Loureiro, J. J. Function and regulation of Ena/VASP proteins. Trends Cell Biol. 13, 386-392 (2003).

27. Gonzalez, G. A. \& Montminy, M. R. Cyclic AMP stimulates somatostatin gene transcription by phosphorylation of CREB at serine 133. Cell 59, 675-680 (1989).

28. Melick, C. H. \& Jewell, J. L. Small molecule H89 renders the phosphorylation of S6K1 and AKT resistant to mTOR inhibitors. Biochem. J. 477, 1847-1863 (2020).

29. Hundsrucker, C. et al. Glycogen synthase kinase 3beta interaction protein functions as an A-kinase anchoring protein. J. Biol. Chem. 285, 5507-5521 (2010).

30. Omar, M. H. \& Scott, J. D. AKAP signaling islands: venues for precision pharmacology. Trends Pharm. Sci. 41, 933-946 (2020).

31. Christian, F. et al. Small molecule AKAP-protein kinase A (PKA) interaction disruptors that activate PKA interfere with compartmentalized cAMP signaling in cardiac myocytes. J. Biol. Chem. 286, 9079-9096 (2011).

32. Carlson, C. R. et al. Delineation of type I protein kinase A-selective signaling events using an RI anchoring disruptor. J. Biol. Chem. 281, 21535-21545 (2006).

33. Wick, A. N., Drury, D. R., Nakada, H. I. \& Wolfe, J. B. Localization of the primary metabolic block produced by 2-deoxyglucose. J. Biol. Chem. 224, 963-969 (1957).

34. Kahana, S. E., Lowry, O. H., Schulz, D. W., Passonneau, J. V. \& Crawford, E. J. The kinetics of phosphoglucoisomerase. J. Biol. Chem. 235, 2178-2184 (1960).

35. Gaitonde, M. K., Murray, E. \& Cunningham, V. J. Effect of 6-phosphogluconate on phosphoglucose isomerase in rat brain in vitro and in vivo. J. Neurochem. 52, 1348-1352 (1989).

36. Rada, P. et al. SCF/\{beta\}-TrCP promotes glycogen synthase kinase 3-dependent degradation of the Nrf2 transcription factor in a Keap1independent manner. Mol. Cell Biol. 31, 1121-1133 (2011).

37. Tanji, C. et al. A-kinase anchoring protein AKAP220 binds to glycogen synthase kinase-3beta (GSK-3beta) and mediates protein kinase A-dependent inhibition of GSK-3beta. J. Biol. Chem. 277, 36955-36961 (2002).

38. Whiting, J. L. et al. Protein kinase A opposes the phosphorylation-dependent recruitment of glycogen synthase kinase 3 beta to A-kinase anchoring protein 220. J. Biol. Chem. 290, 19445-19457 (2015).

39. Tran, H. D. et al. Transient SNAIL1 expression is necessary for metastatic competence in breast cancer. Cancer Res. 74, 6330-6340 (2014).

40. Palmieri, D. et al. Analyses of resected human brain metastases of breast cancer reveal the association between up-regulation of hexokinase 2 and poor prognosis. Mol. Cancer Res. 7, 1438-1445 (2009).

41. Macosko, E. Z. et al. Highly parallel genome-wide expression profiling of individual cells using nanoliter droplets. Cell 161, 1202-1214 (2015).

42. Ariss, M. M., Islam, A., Critcher, M., Zappia, M. P. \& Frolov, M. V. Single cell RNA-sequencing identifies a metabolic aspect of apoptosis in Rbf mutant. Nat. Commun. 9, 5024 (2018).
43. Chen, X. et al. Cell-Autonomous versus Systemic Akt Isoform Deletions Uncovered New Roles for Akt1 and Akt2 in Breast Cancer. Mol. Cell 80, 87-101 e105 (2020).

44. De Craene, B. et al. The transcription factor snail induces tumor cell invasion through modulation of the epithelial cell differentiation program. Cancer Res. 65, 6237-6244 (2005).

45. Come, C. et al. Snail and slug play distinct roles during breast carcinoma progression. Clin. Cancer Res. 12, 5395-5402 (2006).

46. Martinez-Estrada, O. M. et al. The transcription factors Slug and Snail act as repressors of Claudin-1 expression in epithelial cells. Biochem. J. 394, 449-457 (2006).

47. Ni, T. et al. Snail1-dependent p53 repression regulates expansion and activity of tumour-initiating cells in breast cancer. Nat. Cell Biol. 18, 1221-1232 (2016).

48. Aslakson, C. J. \& Miller, F. R. Selective events in the metastatic process defined by analysis of the sequential dissemination of subpopulations of a mouse mammary tumor. Cancer Res. 52, 1399-1405 (1992).

49. Sodi, V. L. et al. Nutrient sensor O-GlcNAc transferase controls cancer lipid metabolism via SREBP-1 regulation. Oncogene 37, 924-934 (2018)

50. Park, S. Y. et al. Snaill is stabilized by O-GlcNAc modification in hyperglycaemic condition. EMBO J. 29, 3787-3796 (2010).

51. Patra, K. C. et al. Hexokinase 2 is required for tumor initiation and maintenance and its systemic deletion is therapeutic in mouse models of cancer. Cancer Cell 24, 213-228 (2013).

52. Nogueira, V., Patra, K. C. \& Hay, N. Selective eradication of cancer displaying hyperactive Akt by exploiting the metabolic consequences of Akt activation. Elife 7, https://doi.org/10.7554/eLife.32213 (2018).

53. Ma, Y. \& Taylor, S. A 15-residue bifunctional element in D-AKAP1 is required for both endoplasmic reticulum and mitochondrial targeting. J. Biol. Chem. 277, 27328-27336 (2002).

54. Wilson, J. E. Hexokinases. Rev. Physiol. Biochem. Pharm. 126, 65-198 (1995).

55. Gu, Y. et al. GlcNAcylation plays an essential role in breast cancer metastasis. Cancer Res. 70, 6344-6351 (2010).

56. Majewski, N., Nogueira, V., Robey, R. B. \& Hay, N. Akt inhibits apoptosis downstream of BID cleavage via a glucose-dependent mechanism involving mitochondrial hexokinases. Mol. Cell Biol. 24, 730-740 (2004).

57. Skeen, J. E. et al. Akt deficiency impairs normal cell proliferation and suppresses oncogenesis in a p53-independent and mTORC1-dependent manner. Cancer Cell 10, 269-280 (2006).

58. Bhaskar, P. T. et al. mTORC1 hyperactivity inhibits serum deprivationinduced apoptosis via increased hexokinase II and GLUT1 expression, sustained Mcl-1 expression, and glycogen synthase kinase 3beta inhibition. Mol. Cell Biol. 29, 5136-5147 (2009).

59. Zhu, A., Romero, R. \& Petty, H. R. An enzymatic fluorimetric assay for glucose-6-phosphate: application in an in vitro Warburg-like effect. Anal. Biochem. 388, 97-101 (2009).

60. Young, L. E. A. et al. Accurate and sensitive quantitation of glucose and glucose phosphates derived from storage carbohydrates by mass spectrometry. Carbohydr. Polym. 230, 115651 (2020).

61. Kind, T. et al. FiehnLib: mass spectral and retention index libraries for metabolomics based on quadrupole and time-of-flight gas chromatography/ mass spectrometry. Anal. Chem. 81, 10038-10048 (2009).

62. Fernandez, C. A., Des Rosiers, C., Previs, S. F., David, F. \& Brunengraber, H Correction of 13C mass isotopomer distributions for natural stable isotope abundance. J. Mass Spectrom. 31, 255-262 (1996).

63. Butler, A., Hoffman, P., Smibert, P., Papalexi, E. \& Satija, R. Integrating singlecell transcriptomic data across different conditions, technologies, and species. Nat. Biotechnol. 36, 411-420 (2018).

64. Travaglini, K. J. et al. A molecular cell atlas of the human lung from single-cell RNA sequencing. Nature 587, 619-625 (2020)

65. Han, X. et al. Mapping the mouse cell atlas by microwell-seq. Cell 172, 1091-1107.e1017 (2018).

66. Subramanian, A. et al. Gene set enrichment analysis: a knowledge-based approach for interpreting genome-wide expression profiles. Proc. Natl Acad Sci. USA 102, 15545-15550 (2005).

\section{Acknowledgements}

N.H. acknowledges the support from NIH grants R01AG016927, R01CA090764, and R01 CA206167, the VA merit award BX000733, and the VA research career scientist award IK6BX004602. C.S.B. acknowledges the support from F30CA228191. H.R. acknowledges the support from the center for clinical and translational science. A.R.T. acknowledges the support from F30CA225058. M.V.F. acknowledges the support from NIH grant R35GM131707. R.B.B acknowledges the support of VA grant NEPH-007-02S. We would like to thank Ling Jin for maintaining and genotyping the mice. The contents do not represent the views of the U.S. Department of Veterans Affairs or the United States Government. 


\section{Author contributions}

N.H. supervised the studies and wrote the manuscript together with C.S.B., S.M.J., and R.B.B. S.M.J. conducted the initial experiments that formed the hypothesis and G.R. conducted all the additional experiments to validate the hypothesis. R.B.B. conducted the yeast two-hybrid screen. C.S.B. conducted all the mouse models experiments, analyzed the tumors, ScRNAseq experiments, and in vitro migration assays. V.N. performed the in vitro binding experiments and helped with the mouse experiments. K.C.P generated the mice. H.R. performed the SNAIL stability experiments and other supporting experiments. S.K. performed the glucose tracing experiments. P.B. and A.R.T. provided supporting experiments. A.F.A and M.V.F performed and analyzed the ScRNAseq.

\section{Competing interests}

The authors declare no competing interests.

\section{Additional information}

Supplementary information The online version contains supplementary material available at https://doi.org/10.1038/s41467-022-28440-3.

Correspondence and requests for materials should be addressed to Sang-Min Jeon or Nissim Hay.
Peer review information Nature Communications thanks the anonymous reviewers for their contribution to the peer review of this work.

Reprints and permission information is available at http://www.nature.com/reprints

Publisher's note Springer Nature remains neutral with regard to jurisdictional claims in published maps and institutional affiliations.

\section{(c) (i)}

Open Access This article is licensed under a Creative Commons Attribution 4.0 International License, which permits use, sharing, adaptation, distribution and reproduction in any medium or format, as long as you give appropriate credit to the original author(s) and the source, provide a link to the Creative Commons license, and indicate if changes were made. The images or other third party material in this article are included in the article's Creative Commons license, unless indicated otherwise in a credit line to the material. If material is not included in the article's Creative Commons license and your intended use is not permitted by statutory regulation or exceeds the permitted use, you will need to obtain permission directly from the copyright holder. To view a copy of this license, visit http://creativecommons.org/ licenses/by/4.0/.

This is a U.S. Government work and not under copyright protection in the US; foreign copyright protection may apply 2022 